Article

\title{
Significant Surface Spin Effects and Exchange Bias in Iron Oxide-Based Hollow Magnetic Nanoparticles
}

\author{
Pelayo García Acevedo ${ }^{1, *(\mathbb{D})}$, Manuel A. González Gómez ${ }^{1} \mathbb{D}^{\mathbb{D}}$, Ángela Arnosa Prieto ${ }^{1}$, Jose S. Garitaonandia ${ }^{2}$, \\ Yolanda Piñeiro ${ }^{1}$ and José Rivas ${ }^{1, * \mathbb{D}}$
}

1 NANOMAG Laboratory, Applied Physics Department, iMATUS Materials Institute, Universidade de Santiago de Compostela, 15782 Santiago de Compostela, Spain; manuelantonio.gonzalez@usc.es (M.A.G.G.); angela.arnosa@usc.es (Á.A.P.); y.pineiro.redondo@usc.es (Y.P.)

2 Faculty of Science and Technology, University of the Basque Country (UPV/EHU), 48940 Leioa, Spain; js.garitaonandia@ehu.eus

* Correspondence: pelayo.garcia.acevedo@usc.es (P.G.A.); jose.rivas@usc.es (J.R.); Tel.: +34-881813097 (P.G.A.); +34-881813062 (J.R.)

check for

updates

Citation: García Acevedo, P.;

González Gómez, M.A.; Arnosa

Prieto, Á.; Garitaonandia, J.S.; Piñeiro,

Y.; Rivas, J. Significant Surface Spin

Effects and Exchange Bias in Iron

Oxide-Based Hollow Magnetic

Nanoparticles. Nanomaterials 2022, 12,

456. https://doi.org/10.3390/

nano12030456

Academic Editor: Fabien Grasset

Received: 5 November 2021

Accepted: 8 January 2022

Published: 28 January 2022

Publisher's Note: MDPI stays neutral with regard to jurisdictional claims in published maps and institutional affiliations.

Copyright: () 2022 by the authors Licensee MDPI, Basel, Switzerland. This article is an open access article distributed under the terms and conditions of the Creative Commons Attribution (CC BY) license (https:// creativecommons.org/licenses/by/ $4.0 /)$.

\begin{abstract}
Exchange bias (EB) properties have become especially important in hollow magnetic nanoparticles (MNPs) due to the versatility and reduced size of these materials. In this work, we present the synthesis and study of the EB properties of iron-oxide-based hollow MNPs and their precursors Fe/iron oxide MNPs with core/void/shell structure. The two mechanisms involved in EB generation were investigated: the frozen spins present in the nanograins that form the nanoparticles and the surface spins. The effect of external parameters on the coercivity $\left(\mathrm{H}_{\mathrm{C}}\right)$, remanence $\left(\mathrm{M}_{\mathrm{R}}\right)$, exchange bias field $\left(\mathrm{H}_{\mathrm{EB}}\right)$ and frozen spins, such as cooling field $\left(\mathrm{H}_{\mathrm{FC}}\right)$ and temperature, was investigated. Both $\mathrm{H}_{\mathrm{C}}$ and $\mathrm{H}_{\mathrm{EB}}$ present a maximum threshold above which their values begin to decrease with $\mathrm{H}_{\mathrm{FC}}$, showing a new trend of $\mathrm{H}_{\mathrm{EB}}$ with $\mathrm{H}_{\mathrm{FC}}$ and allowing modulation on demand. The existence of surface spins, present on the outer and inner surfaces, was demonstrated, and an intrinsic EB phenomenon $\left(\mathrm{H}_{\mathrm{EB}}=444\right.$ Oe for hollow iron oxide-based MNPs of $\left.13.1 \mathrm{~nm}\right)$ with significant magnetization $\left(\mathrm{M}_{\mathrm{S}} \sim 50 \mathrm{emu} / \mathrm{g}\right)$ was obtained. Finally, core/void/shell MNPs of $11.9 \mathrm{~nm}$ prior to the formation of the hollow MNPs showed a similar behavior, with non-negligible $\mathrm{H}_{\mathrm{EB}}$, highlighting the importance of surface spins in EB generation.
\end{abstract}

Keywords: magnetic nanoparticles; nanomagnetism; exchange bias; surface spins; interfacial effects

\section{Introduction}

Exchange bias is a magnetic phenomenon in which magnetic phases of different character are coupled via exchange interaction and their magnetic behavior departs from a simple response, giving rise to a shift from the zero-field position of the hysteresis loop at low temperatures. Although interest in EB is growing, owing to its technological applications in the electronic field (spintronic devices [1], spin valves [2], magnetoresistive random-access memory (MRAM) circuits [3]), or new recording media [4] based on materials where the superparamagnetic limit could be defeated with the help of EB-tailored properties, the detailed understanding of EB is still poorly understood.

Initially, the prototypical magnetic system showing EB was a ferromagnetic (FM)/ antiferromagnetic (AFM) binary system, cooled through the Néel temperature under the application of an external magnetic field [5-7]. Subsequently, it was further observed in other binary systems at the interface of ferromagnetic/ferrimagnetic (FM/FI) [8] or antiferromagnetic/ferrimagnetic (AF/FI) [9] materials. Despite this, most efforts have been focused on studying the EB phenomenon in thin-layer systems; and since its observation in MNPs in 1956 [10], the interest in EB in nanomaterials has increased. In recent years, the improvement of MNP synthesis, which allows the production of MNPs with strict size and shape control, has turned relevant MNPs into interesting tools to study fundamental EB 
mechanisms and alternative solutions for small size applications. In fact, the possibility to produce solid cores, core@shell, and hollow nanostructures allows the study of the cross-over contribution of a different set of mechanisms related to EB: surface spin disorder and exchange coupling of different magnetic phases.

The impact of size reduction on the magnetic properties of solid MNPs, caused by the large contribution of a disordered surface spin layer, has been widely studied for different materials, such as $\mathrm{CoFe}_{2} \mathrm{O}_{4}$ MNPs of $4.5 \mathrm{~nm}\left(\mathrm{H}_{\mathrm{EB}}=735 \mathrm{Oe}\right)$ [11] or NiO MNPs of $4 \mathrm{~nm}$ $\left(\mathrm{H}_{\mathrm{EB}}=900 \mathrm{Oe}\right)$ [12], and, more intensely, in $\gamma-\mathrm{Fe}_{2} \mathrm{O}_{3} \mathrm{MNPs}$ [13-16]. EB observed in solid MNPs is attributed to the exchange coupling between disordered surface spins that may become frozen in a spin-glass-like state and inner-ordered spins [5]. In Fe oxide-based MNPs, significant differences in magnetization have been found between small ( $5 \mathrm{~nm}$ ) $\mathrm{Fe}_{3} \mathrm{O}_{4}$ and $\gamma-\mathrm{Fe}_{2} \mathrm{O}_{3}$ MNPs $[17,18]$, owing to the notable contribution of surface effects at this size scale and the fact that surface spin disorder is stronger in $\gamma-\mathrm{Fe}_{2} \mathrm{O}_{3} \mathrm{MNPs}$ than in $\mathrm{Fe}_{3} \mathrm{O}_{4}$ MNPs [5]. Although EB effects, ascribed to exchange coupling between the disordered surface and antiferromagnetically ordered structure of the core [19], have been observed in $\gamma-\mathrm{Fe}_{2} \mathrm{O}_{3}$ MNPs, and also in $\mathrm{Fe}_{3} \mathrm{O}_{4}$ MNPs, their detailed understanding in terms of size remains elusive owing to contradictory reported data. Systematic studies of the size effects related to $\mathrm{EB}$ in small $\mathrm{Fe}_{3} \mathrm{O}_{4} \mathrm{MNPs}$, of $4,6,8,10$, and $12 \mathrm{~nm}$, only report EB effects $\left(\mathrm{H}_{\mathrm{EB}}=750 \mathrm{Oe}\right)$ in the smaller samples $(4 \mathrm{~nm})$ [18]. Equally sized small $(8 \mathrm{~nm}) \mathrm{Fe}_{3} \mathrm{O}_{4}$ and $\gamma-\mathrm{Fe}_{2} \mathrm{O}_{3}$ MNPs [20] show larger and stronger surface disorder in $\gamma-\mathrm{Fe}_{2} \mathrm{O}_{3}$ and should provide higher $\mathrm{H}_{\mathrm{EB}}$. Moreover, as the size of $\gamma-\mathrm{Fe}_{2} \mathrm{O}_{3} \mathrm{MNPs}$ increases, $7 \mathrm{~nm}$ [21], $8 \mathrm{~nm}$ [20], $10 \mathrm{~nm}$ [22], they show an increasing $\mathrm{EB}, \mathrm{H}_{\mathrm{EB}}=60(\mathrm{Oe}), \mathrm{H}_{\mathrm{EB}}=267(\mathrm{Oe}), \mathrm{H}_{\mathrm{EB}}=1500(\mathrm{Oe})$, respectively, for decreasing surface spin. Although surface effects and magnetic frustration are more noticeable as the size of MNPs is reduced, a defined relationship between size and $\mathrm{H}_{\mathrm{EB}}$ cannot be established from the data reported in previous research, since EB depends in a complex way on other factors, such as shape or magnetic interactions [5]. Besides this, since EB in solid MNPs requires surface spin effects that become relevant in MNPs with a large size reduction, the consequence of this entails a reduction in magnetization [18]. Therefore, new types of MNP with EB properties, such as core/shell MNPs with a coupling between the core and the shell [23], or hollow MNPs, with an additional layer of surface spins contributing to increased spin disorder [24], can be envisaged as alternative systems showing EB and moderate magnetization simultaneously.

Core/shell MNPs, such as thin-layer systems, have been reported to show EB, mainly due to the exchange coupling between different magnetic materials: $\mathrm{Fe} / \gamma-\mathrm{Fe}_{2} \mathrm{O}_{3}$ with particle sizes of $15 \mathrm{~nm}\left(\mathrm{H}_{\mathrm{EB}}=1.6 \mathrm{kOe}\right), 10 \mathrm{~nm}\left(\mathrm{H}_{\mathrm{EB}}=3.5 \mathrm{kOe}\right)$ and $8 \mathrm{~nm}\left(\mathrm{H}_{\mathrm{EB}}=3200 \mathrm{Oe}\right)$ [25]; $\mathrm{Fe} / \mathrm{Fe}_{3} \mathrm{O}_{4}$ MNPs of $13.8 \mathrm{~nm}\left(\mathrm{H}_{\mathrm{EB}}=1190 \mathrm{Oe}\right)$ [23]; $\mathrm{FeO} / \mathrm{Fe}_{3} \mathrm{O}_{4} \mathrm{MNPs}$ of $10 \mathrm{~nm}\left(\mathrm{H}_{\mathrm{EB}}=1700 \mathrm{Oe}\right)$ [26]; $\mathrm{Fe}_{3} \mathrm{O}_{4} / \gamma-\mathrm{Fe}_{2} \mathrm{O}_{3} \mathrm{MNPs}$ of $12 \mathrm{~nm}\left(\mathrm{H}_{\mathrm{EB}}=270 \mathrm{Oe}\right)$ [27] or $\mathrm{CoO} / \mathrm{Fe}_{3} \mathrm{O}_{4} \mathrm{MNPs}$ [28]. Different magnetite-based systems, combining an antiferromagnetic core $(\mathrm{FeO})$ and a ferrimagnetic shell $\left(\mathrm{Fe}_{3} \mathrm{O}_{4}\right)$ in a wide range of sizes $(10-35 \mathrm{~nm})$ [26,29-31], have been explored to produce tailored $\mathrm{EB}$ (Xiaolian Sun et al. [30] have reported $\mathrm{H}_{\mathrm{EB}}=2260$ Oe in $\mathrm{FeO} / \mathrm{Fe}_{3} \mathrm{O}_{4} \mathrm{MNPs}$ of $35 \mathrm{~nm}$ ). However, in addition to the core/shell coupling, the surface effects become relevant and even dominant in EB. In fact, a critical particle size in $\mathrm{Fe} / \gamma-\mathrm{Fe}_{2} \mathrm{O}_{3} \mathrm{MNPs}$, in which the interface spin effect contributes primarily to the EB, but below which the surface spin effect dominates, has been established by keeping the shell thickness $(2 \mathrm{~nm})$ fixed and varying the core size (4-11 nm) [25]. However, different studies aiming to assess the importance of surface spins in the EB of core/shell NPs provide contradictory results. On one hand, it was stated that no substantial modification of $\mathrm{H}_{\mathrm{EB}}$ was observed between the core/shell and void/shell system after removing the core in $\mathrm{Fe} / \gamma-\mathrm{Fe}_{2} \mathrm{O}_{3} \mathrm{MNPs}$ [32], while in different works, a drastic reduction in $\mathrm{H}_{\mathrm{EB}}$ was observed in core/shell MNPs after keeping only the $\mathrm{Fe}_{3} \mathrm{O}_{4}$ shell, showing the low importance of surface spins in this type of systems $[5,23,33]$.

The transformation from core/shell MNPs to hollow MNPs using the Kirkendall effect [33], is a useful chemical tool to create nanostructures with tailored surface-volume ratios to further analyze EB in hollow MNPs. Although EB in hollow MNPs was firstly attributed only to the large portion of disordered spins located in the inner and outer 
shells [5], other studies show that the interfaces between the crystallographic domains of MNPs may also play an important role [34]. Although $\mathrm{H}_{\mathrm{EB}}$ has been studied in hollow MNPs with diverse compositions, such as $\mathrm{CoFe}_{2} \mathrm{O}_{4}\left(\mathrm{H}_{\mathrm{EB}}=733 \mathrm{Oe}\right)$ [35], $\mathrm{NiFe}_{2} \mathrm{O}_{4}$ $\left(\mathrm{H}_{\mathrm{EB}}=301 \mathrm{Oe}\right)$ [36] or $\mathrm{Fe}_{3} \mathrm{O}_{4}\left(\mathrm{H}_{\mathrm{EB}}=133 \mathrm{Oe}\right)$ [23], studies on $\gamma-\mathrm{Fe}_{2} \mathrm{O}_{3}$ hollow MNPs are the most abundant $[13,24,34,37]$. A large hysteresis loop shift has been reported in hollow $\gamma-\mathrm{Fe}_{2} \mathrm{O}_{3}$ as small as $8.2 \mathrm{~nm}$ [37], $9.2 \mathrm{~nm}$ [34], and $9.4 \mathrm{~nm}$ [32]. However, since the maximum applied field is smaller than the irreversibility field, these shifts correspond to a minor loop and not an intrinsic EB effect. In addition, a significant loop shift (7000 Oe) was also reported in larger $\gamma-\mathrm{Fe}_{2} \mathrm{O}_{3}$ hollow MNPs $(14.7 \mathrm{~nm})$ [32]. On the other hand, an intrinsic EB phenomenon has been reported in larger $\gamma-\mathrm{Fe}_{2} \mathrm{O}_{3}$ hollow MNPs $(18.7 \mathrm{~nm})$ [34] However, the $\mathrm{H}_{\mathrm{EB}}$ obtained is significantly lower than the loop shifts obtained in ultrathin hollow $\gamma-\mathrm{Fe}_{2} \mathrm{O}_{3}$ with minor loop effects. Large differences were reported between the surface spin contributions above the magnetic properties in hollow $\gamma-\mathrm{Fe}_{2} \mathrm{O}_{3}$ MNPs of 9 and $18 \mathrm{~nm}$, obtaining a percentage of surface spins of 87 and $3 \%$ for the $\gamma-\mathrm{Fe}_{2} \mathrm{O}_{3}$ MNPs of $9 \mathrm{~nm}$ (minor loop) and $18 \mathrm{~nm}$ (EB), respectively [32]. This suggests that a greater presence of surface spins contributes significantly to minor loop generation and not to EB. However, interestingly, F. Sayed et al. [38] recently reported the existence of an intrinsic EB effect in ultrathin hollow $\gamma-\mathrm{Fe}_{2} \mathrm{O}_{3}$ MNPs $(9.4 \mathrm{~nm})$. From Mossbauer experiments, the disorder of surface spins was shown and through Monte Carlo simulations, the fundamental role of the surface anisotropy in the noncollinearity of the spin structure was corroborated. In addition, F. Sayed et al. [24] reported a computer model of hollow MNPs as a function of size and shell thickness. The influence of the shell thickness of hollow MNPs on the spin configuration was reported, with the conclusion that the superficial anisotropy (from both the internal and external surfaces) becomes larger as the shell diminishes. In addition, a $\mathrm{H}_{\mathrm{EB}}=133 \mathrm{Oe}$ value in $16.0 \mathrm{~nm}$ hollow $\mathrm{Fe}_{3} \mathrm{O}_{4}$ MNPs was reported by Ong et al. [23], the only recent study to report $\mathrm{EB}$ in hollow $\mathrm{Fe}_{3} \mathrm{O}_{4} \mathrm{MNPs}$. However, due to the small size of hollow $\gamma-\mathrm{Fe}_{2} \mathrm{O}_{3}(<10 \mathrm{~nm})$, the surface effects led to a significant magnetization reduction of MNPs. In addition, large differences between the minor loop effect and intrinsic EB were observed in hollow MNPs. Therefore, more experimental studies of hollow MNPs with an intrinsic EB and with significant magnetization to improve its application should be carried out.

Exchange bias generation in MNPs is affected by several factors, such as particle size, the thickness of the shell in core/shell MNPs or in hollow MNPs, temperature, cooling field $\left(\mathrm{H}_{\mathrm{FC}}\right)$, morphology, and composition [5]. Especially important is the effect of temperature and $\mathrm{H}_{\mathrm{FC}}$ on modifying $\mathrm{EB}$, since it is an externally controllable factor in obtaining $\mathrm{H}_{\mathrm{EB}}$ on demand. Temperature dependence has been widely demonstrated, showing a reduction in the EB effect with increasing temperature $[5,21,22,25,32,39]$. Despite the numerous EB studies reported on MNPs, there is no well-defined trend in $\mathrm{H}_{\mathrm{EB}}$ dependence with $\mathrm{H}_{\mathrm{FC}}$. While in $\mathrm{Fe} / \mathrm{Fe}_{3} \mathrm{O}_{4}$ MNPs, $\mathrm{H}_{\mathrm{EB}}$ grows with $\mathrm{H}_{\mathrm{FC}}\left(\mathrm{H}_{\mathrm{FC}} \mathrm{Max}=10 \mathrm{kOe}\right)$ [23], in $\mathrm{CoFe}_{2} \mathrm{O}_{4} \mathrm{MNPs}$ an $\mathrm{H}_{\mathrm{EB}}$ maximum has been observed at $\mathrm{H}_{\mathrm{FC}}=5 \mathrm{kOe}$ (lower than $\mathrm{H}_{\mathrm{FC}}{ }^{\mathrm{Max}}=15 \mathrm{kOe}$ ) [40]. A similar trend was observed in $\mathrm{Fe}_{3} \mathrm{O}_{4} \mathrm{MNPs}$. However, the $\mathrm{H}_{\mathrm{EB}}$ maximum was reported at a higher $\mathrm{H}_{\mathrm{FC}}(30 \mathrm{kOe})$ [41]. In addition, $\mathrm{H}_{\mathrm{EB}}$ dependence with $\mathrm{H}_{\mathrm{FC}}$ up to $50 \mathrm{kOe}$ in a granular system of $\mathrm{Fe}$ nanoparticles was investigated, showing a $\mathrm{H}_{\mathrm{EB}}$ maximum at 4 kOe [42]. Despite the multiple efforts made in EB generation in hollow $\gamma-\mathrm{Fe}_{2} \mathrm{O}_{3} \mathrm{MNPs}$, to our knowledge, no studies of $\mathrm{H}_{\mathrm{EB}}$ dependence with $\mathrm{H}_{\mathrm{FC}}$ have been reported. It is therefore necessary to carry out more studies in this area.

Numerous studies have reported a hysteresis loop shift in hollow iron-oxide-based MNPs. However, many have been attributed to a minor loop effect and not an intrinsic effect of EB, especially in hollow $\gamma-\mathrm{Fe}_{2} \mathrm{O}_{3}$ MNPs. In addition, due to the small size of hollow $\gamma-\mathrm{Fe}_{2} \mathrm{O}_{3} \mathrm{MNPs}(<10 \mathrm{~nm})$, the surface effects lead to a significant magnetization reduction of MNPs and the maximum magnetization of these MNPs is very low $(9.2 \mathrm{~nm}$, $\mathrm{M}_{\mathrm{MAX}}<1 \mathrm{emu} / \mathrm{g}$ [38]; $9.2 \mathrm{~nm}, \mathrm{M}_{\mathrm{MAX}} \sim 1 \mathrm{emu} / \mathrm{g}$ [34]; $9.4 \mathrm{~nm}, \mathrm{M}_{\mathrm{MAX}} \sim 1.2 \mathrm{emu} / \mathrm{g}$ [32]; $8.2 \mathrm{~nm}$, $\mathrm{M}_{\mathrm{MAX}} \sim 6 \mathrm{emu} / \mathrm{g}$ [37]). These combinations of minor loops instead of intrinsic EB and reduced magnetization may be a drawback in the use of hollow $\gamma-\mathrm{Fe}_{2} \mathrm{O}_{3}$ MNPs for several 
applications. Therefore, in order to gain insights on $\mathrm{EB}$ in hollow $\gamma-\mathrm{Fe}_{2} \mathrm{O}_{3}$ or $\mathrm{Fe}_{3} \mathrm{O}_{4} \mathrm{MNPs}$, systematic studies are required to assess different aspects of $\mathrm{H}_{\mathrm{EB}}$ and its dependence with extended values of $\mathrm{H}_{\mathrm{FC}}$, since the current field is very limited.

In the present work, an intrinsic $\mathrm{EB}$ effect $\left(\mathrm{H}_{\mathrm{EB}}=444 \mathrm{Oe}\right)$ in iron oxide-based hollow MNPs of $13.1 \mathrm{~nm}$ with a significant magnetization (around $50 \mathrm{emu} / \mathrm{g}$ ) is studied in detail. The dependence of $\mathrm{H}_{\mathrm{C}}, \mathrm{M}_{\mathrm{R}}$ and $\mathrm{H}_{\mathrm{EB}}$ with $\mathrm{H}_{\mathrm{FC}}$ and temperature using $\mathrm{H}_{\mathrm{FC}}$ up to $50 \mathrm{kOe}$, as well as the variation in the number of frozen spins with $\mathrm{H}_{\mathrm{FC}}$ and temperature, were investigated to shed light on the field-cooling effects on EB, producing new results not reported so far in iron oxide hollow MNPs. In addition, the presence of surface spins as a new way to improve the EB properties of hollow MNPs was studied. To understand in depth the EB generation mechanism, a detailed study of the magnetic properties of the precursor core/void/shell MNPs (with Fe core) was performed prior to the complete oxidation of the Fe core, allowing us to shed light on EB generation in hollow iron-oxidebased MNPs.

\section{Materials and Methods}

\subsection{Chemicals and Materials}

Chemicals used for this study were iron (0) pentacarbonyl $\left(\mathrm{Fe}(\mathrm{CO})_{5},>99.99 \%\right)$, oleylamine $\left(\mathrm{C}_{18} \mathrm{H}_{35} \mathrm{NH}_{2}, 80-90 \%\right)$, 1-octadecene $\left(\mathrm{C}_{18} \mathrm{H}_{36}, 90 \%\right)$, trimethylamine $\mathrm{N}$-oxide $\left(\left(\mathrm{CH}_{3}\right)_{3} \mathrm{NO}, 98 \%\right)$, and hexane $\left(\mathrm{CH}_{3}\left(\mathrm{CH}_{2}\right)_{4} \mathrm{CH}_{3},>95 \%\right.$ ), all obtained from Sigma-Aldrich (Burlington, MA, USA).

\subsection{Synthesis of Core/Void/Shell Nanoparticles (Fe/Iron Oxide)}

MNPs were obtained following Peng's method [43] with some modifications. In a typical synthesis, 1-octadecene $(200 \mathrm{~mL})$ and oleylamine $(3 \mathrm{~mL}, 9.12 \mathrm{mmol})$ were degassed under nitrogen at $120^{\circ} \mathrm{C}$ for $3 \mathrm{~h}$ to eliminate the oxygen of the mixture. After that, the solution was heated until $180^{\circ} \mathrm{C}$ and iron pentacarbonyl $(7 \mathrm{~mL}, 53.2 \mathrm{mmol})$ was quickly added under nitrogen. The reaction was kept at $180^{\circ} \mathrm{C}$ for $40 \mathrm{~min}$. The mixture was cooled naturally to room temperature.

\subsection{Synthesis of Hollow Magnetic Nanoparticles (Iron Oxide)}

Hollow MNPs were prepared by adding trimethylamine N-oxide (400 mg) and 1octadecene $(200 \mathrm{~mL})$ in a three-necked round flask. The mixture was degassed with nitrogen throughout the procedure and mechanically stirred. The reaction was heated at $130{ }^{\circ} \mathrm{C}$ for $1 \mathrm{~h}$, followed by quickly adding core/void/shell (C/V/S) MNPs (800 mg) dispersed in hexane into the mixture and heated for $2 \mathrm{~h}$ to remove the hexane and it was heated at $210{ }^{\circ} \mathrm{C}$ for $4 \mathrm{~h}$. The product was allowed to cool down to room temperature.

Oleylamine was used in both MNPs as a functional coating in order to avoid direct interactions between the MNPs.

\subsection{Physicochemical and Magnetic Characterization of Core/Void/Shell and Hollow MNPs}

The characterization of the crystalline phases of the MNPs was performed by X-ray diffraction (XRD) on powder samples with a Philips PW1710 diffractometer (Panalytical, Brighton, UK) and a Cu K $\mathrm{a}_{\mathrm{a}}$ radiation source, $\lambda=1.54186 \AA$. Measurements were collected in the $2 \theta$ angle range between 10 and $80^{\circ}$ with steps of $0.02^{\circ}$ and $10 \mathrm{~s}$ per step. Morphology of the MNPs was characterized by transmission electron microscopy (TEM) images using a JEOL JEM-1011 microscope (JEOL, Tokyo, Japan) at $100 \mathrm{kV}$. Iron content of the MNPs was determined by flame atomic absorption spectroscopy (FAAS) in a Perkin Elmer 3110 Atomic Absorption Spectrometer (Waltham, MA, USA). Fourier transform infrared (FTIR) spectra were recorded in a Thermo Nicolet Nexus spectrometer (Thermo Fisher Scientific, Madrid, Spain) using the attenuated total reflectance (ATR) method. Mössbauer spectroscopy measurements were performed at room temperature in transmission geometry using a conventional constant-acceleration spectrometer with ${ }^{57} \mathrm{Co}-\mathrm{Rh}$ source. The isomer shift values were taken with respect to an $\alpha$-Fe calibration foil measured at room temperature. NORMOS Mössbauer fitting program (version 16.07.2001) developed by Brand et al. [44] 
was used for fitting the spectra. AC magnetization curves of dried samples were measured using a Quantum Design Physical Property Measurement System (PPMS) (Quantum Design, Darmstadt, Germany) in a temperature range of 10-300 K with steps of $10 \mathrm{~K}$, an excitation field of $1 \mathrm{Oe}$ and driving frequencies varying from $10 \mathrm{~Hz}$ to $1 \mathrm{kHz}$. DC magnetization curves of dried samples were measured using a Superconducting Quantum Interference Device (SQUID) Magnetometer (Quantum Design, Darmstadt, Germany). Measurements of the MNPs magnetization were made in field-cooled (FC) and zero-fieldcooled (ZFC) conditions employing different cooling fields $\left(\mathrm{H}_{\mathrm{FC}}=0.1-50 \mathrm{kOe}\right)$ and as a function of temperature $(\mathrm{T}=5-300 \mathrm{~K})$. The effect of temperature and applied cooling field on the hysteresis loops $(\mathrm{H}= \pm 50 \mathrm{kOe})$ for the MNPs was analysed.

\section{Results and Discussion}

\subsection{Structural, Chemical, and Morphological Properties}

\subsubsection{XRD Characterization}

Figure 1a shows the powder XRD patterns of the C/V/S (black pattern) and the hollow MNPs (red pattern). The position and relative intensities of the main peaks could indicate the presence of magnetite with inverse spinel structure (JCPDS card No. 79-0417) [45]. However, this iron oxide phase could also be associated with maghemite, since these two oxides cannot be distinguished from XRD. The magnetite and maghemite have almost identical or closely crystal structures. Furthermore, 110 and 200 reflections from iron with cubic structure can be observed in the C/V/S MNPs (JCPDS card No. 89-4184) [46].
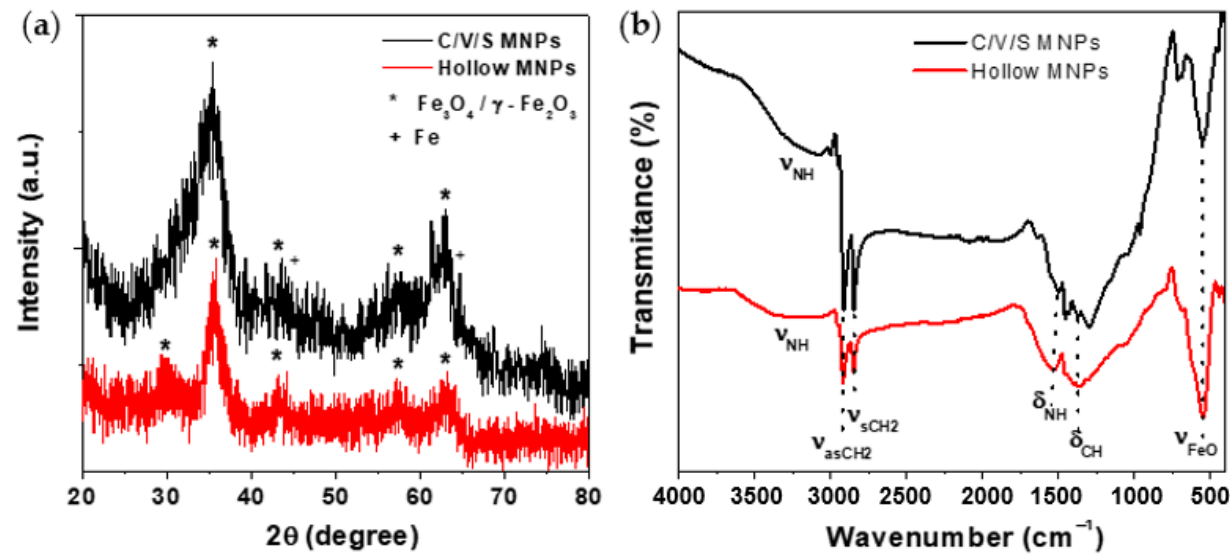

Figure 1. (a) XRD pattern of $C / V / S$ (black pattern) and hollow (red pattern) MNPs, compared to the XRD pattern of magnetite/maghemite $\left(^{*}\right)$ from JCPDS 79-0417 and iron (+) from JCPDS 89-4184 data bases. (b) FT-IR spectra of C/V/S (black pattern) and hollow (red pattern) MNPs.

A lower crystallinity was observed in C/V/S MNPs due to the greater width of the main peak of the XRD pattern. This fact is consistent with the synthesis process of MNPs described by Peng et al. [43], which started from a completely amorphous core/shell MNPs before the crystallinity increased as the C/V/S MNPs were transformed into hollow MNPs. In this study, it was observed that C/V/S MNPs are in an intermediate state of crystallinity between completely amorphous core/shell MNPs and crystalline hollow MNPs. This made it possible to show that in $\mathrm{C} / \mathrm{V} / \mathrm{S}$ MNPs, the oxidation process of the Fe core begins prior to the complete oxidation of the Fe core and the formation of the hollow iron oxide MNPs.

\subsubsection{FT-IR Spectroscopy}

The FT-IR spectra of the hollow MNPs and the C/V/S precursor MNPs are shown in Figure $1 \mathrm{~b}$, black pattern (C/V/S MNPs) and red pattern (hollow MNPs). The FTIR spectra of both samples show a broad absorption band around $3327 \mathrm{~cm}^{-1}$, which is characteristic of the stretching vibrations of the O-H group attributed to the presence of hydroxyl residue, which is due to atmospheric moisture [47]. In addition, the peaks appearing at 2920 and 
2849 , and 1550 and $1305 \mathrm{~cm}^{-1}$, are assigned to the stretching vibrations of $-\mathrm{CH}_{2}$ (asymmetric and symmetric) and the scissoring vibrations (N-H and -C-H) of oleylamine [48], respectively. This oleylamine coating makes it possible to avoid direct interactions between MNPs and their effect on EB generation. Furthermore, the peak at about $550 \mathrm{~cm}^{-1}$ is characteristic of the stretching vibration of $\mathrm{Fe}_{3} \mathrm{O}_{4}$ [49].

\subsubsection{Transmission Electron Microscopies (TEM)}

Figure 2 shows TEM micrographs of (a) the precursor C/V/S and (b) the hollow MNPs. The insets show high-resolution TEM images (HRTEM). A regular spherical morphology with a relatively wide size distribution of around $11.9 \pm 0.9 \mathrm{~nm}$ (C/V/S MNPs) and $13.2 \pm$ $0.7 \mathrm{~nm}$ (hollow MNPs) was obtained. A void space can be observed between the Fe core and the iron oxide shell, suggesting a core/void/shell morphology. On the other hand, in Figure $2 b$, the hollow morphology of the MNPs can be observed due to the darker color of the shell.
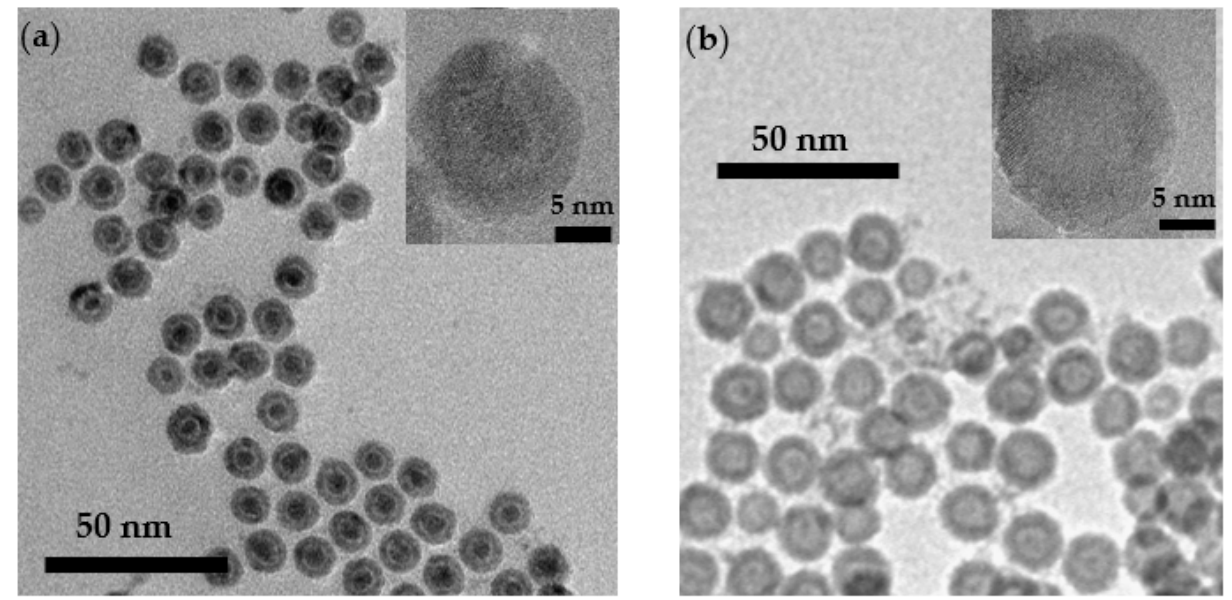

Figure 2. TEM micrograph of (a) core/void/shell and (b) hollow iron oxide MNPs dispersed in hexane. The size distribution was performed using the ImageJ software and shows particle sizes of $11.9 \pm 0.9 \mathrm{~nm}$ for core/void/shell MNPs and $13.2 \pm 0.7 \mathrm{~nm}$ for hollow iron oxide based MNPs. Insets shows HRTEM images of MNPs.

From the HRTEM and TEM micrographs it is possible to obtain the shell thickness, as well as the inner and outer radius of both MNPs. Table 1 shows the morphological values of the MNPs. Shell thicknesses of $2.4 \pm 0.3 \mathrm{~nm}$ for C/V/S MNPs and $3.7 \pm 0.3 \mathrm{~nm}$ for hollow MNPs were obtained, showing a shell increase. Furthermore, a Fe core size of $4.5 \pm$ $0.5 \mathrm{~nm}$ and a void between the core and the shell of $1.3 \pm 0.2 \mathrm{~nm}$ were obtained in $\mathrm{C} / \mathrm{V} / \mathrm{S}$ MNPs. From these values, the surface-to-volume (S/V) ratio can be obtained from the following expressions:

$$
\begin{gathered}
\mathrm{R}_{\text {Hollow }}=\frac{\mathrm{S}}{\mathrm{V}_{\text {shell }}}=\frac{\mathrm{S}_{\text {Outer }}+\mathrm{S}_{\text {inner }}}{\mathrm{V}_{\text {Total }}-\mathrm{V}_{\text {inner }}} \\
\mathrm{R}_{\mathrm{C} / \mathrm{V} / \mathrm{S}}=\frac{\mathrm{S}}{\mathrm{V}_{\text {shell }}+\mathrm{V}_{\text {Core }}}=\frac{\mathrm{S}_{\text {Outer }}+\mathrm{S}_{\text {inner }}+\mathrm{S}_{\text {core }}}{\left(\mathrm{V}_{\text {Total }}-\mathrm{V}_{\text {inner }}\right)+\mathrm{V}_{\text {Core }}}
\end{gathered}
$$

where $S_{\text {outer }}$ and $S_{\text {inner }}$ correspond to the outer and inner surface of the shell and $S_{\text {core }}$ and $\mathrm{V}_{\text {core }}$ correspond to the surface and volume of the Fe core, respectively. 
Table 1. Inner radius $\left(R_{\text {outer }}\right)$, outer radius $\left(R_{\text {inner }}\right)$, core radius $\left(R_{\text {Core }}\right)$, shell thickness $\left(\delta_{\text {shell }}\right)$, void thickness $\left(\mathrm{d}_{\mathrm{void}}\right)$ and surface-to-volume ratio $(\mathrm{S} / \mathrm{V})$ values of MNPs.

\begin{tabular}{ccccccc}
\hline & $\begin{array}{c}\mathbf{R}_{\text {outer }} \\
(\mathbf{n m})\end{array}$ & $\begin{array}{c}\mathbf{R}_{\text {inner }} \\
(\mathbf{n m})\end{array}$ & $\mathbf{R}_{\text {Core }}(\mathbf{n m})$ & $\boldsymbol{\delta}_{\text {shell }}(\mathbf{n m})$ & $\boldsymbol{\delta}_{\text {void }}(\mathbf{n m})$ & $\mathbf{S} / \mathbf{V}$ \\
\hline Hollow & 6.6 & 2.9 & - & 3.7 & 5.8 & 0.6 \\
\hline Core/void/shell & 6.0 & 3.6 & 2.3 & 2.4 & 1.3 & 0.9 \\
\hline
\end{tabular}

The surface-to-volume ratio is higher for the $\mathrm{C} / \mathrm{V} / \mathrm{S}$ MNPs $(\mathrm{S} / \mathrm{V}=0.9)$ than for the hollow MNPs $(S / V=0.6)$, due to the smaller size of the $C / V / S$ MNPs and the contribution of the Fe core surface. This suggests greater disorder and magnetic frustration in the $\mathrm{C} / \mathrm{V} / \mathrm{S}$ MNPs.

\subsubsection{Room Temperature Mössbauer Spectra}

Figure 3 shows the Mössbauer spectrum corresponding to the hollow iron oxide MNPs obtained at room temperature.

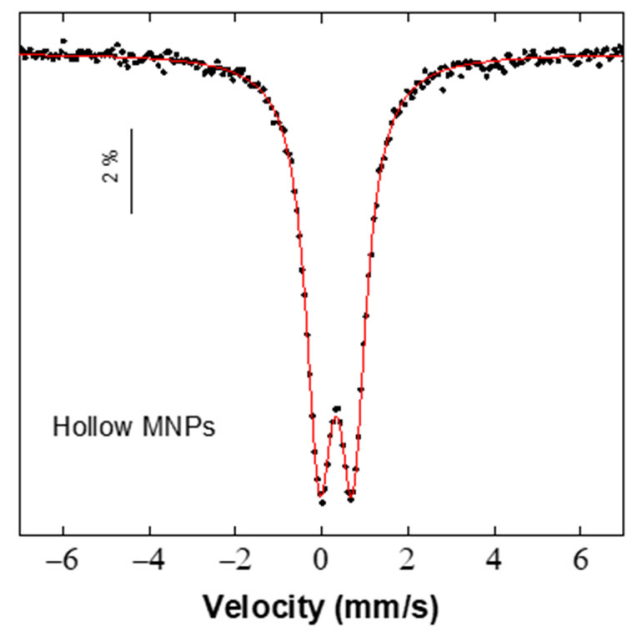

Figure 3. Room temperature ${ }^{57} \mathrm{Fe}$ Mössbauer spectrum of superparamagnetic hollow iron oxide MNPs.

The spectrum of hollow MNPs is characterized by a well resolved doublet and the absence of other any additional component, as expected from samples composed by homogenously sized MNPs well above the blocking temperature $\left(T_{B}\right)$ in a superparamagnetic regimen. Hyperfine parameters, with an isomer shift (IS) of $0.33 \mathrm{~mm} / \mathrm{s}$, quadrupolar splitting (QS) of $0.76 \mathrm{~mm} / \mathrm{s}$, and a linewidth of $0.75 \mathrm{~mm} / \mathrm{s}$ were obtained for the hollow iron oxide MNPs. Spectra with these hyperfine parameters are commonly observed in systems composed by superparamagnetic magnetite-precursor MNPs [50] and in low-dimensional magnetite MNPs systems with high surface/core ratio [51,52].

\subsection{Magnetic Properties}

In order to understand the DC magnetic properties of the C/V/S MNPs and hollow MNPs, hysteresis loops were performed as the temperature reduced from 300 to $10 \mathrm{~K}$. Figure 4 shows the hysteresis loops of the C/V/S MNPs (Figure 4a) and the hollow MNPs (Figure $4 \mathrm{~b}$ ) at different temperatures: $10 \mathrm{~K}$ (light blue), $50 \mathrm{~K}$ (dark blue), $100 \mathrm{~K}$ (red), $200 \mathrm{~K}$ (gray), and $300 \mathrm{~K}$ (black). These were performed with a SQUID magnetometer between -50 and $+50 \mathrm{kOe}$. The insets show the low-field region in more detail, where the coercivity and remanence of both samples can be observed. Neither MNP presented saturation, despite the use of very high fields, $\pm 50 \mathrm{kOe}$, and a noticeable paramagnetic contribution can be observed in the hysteresis loops. 
(a)

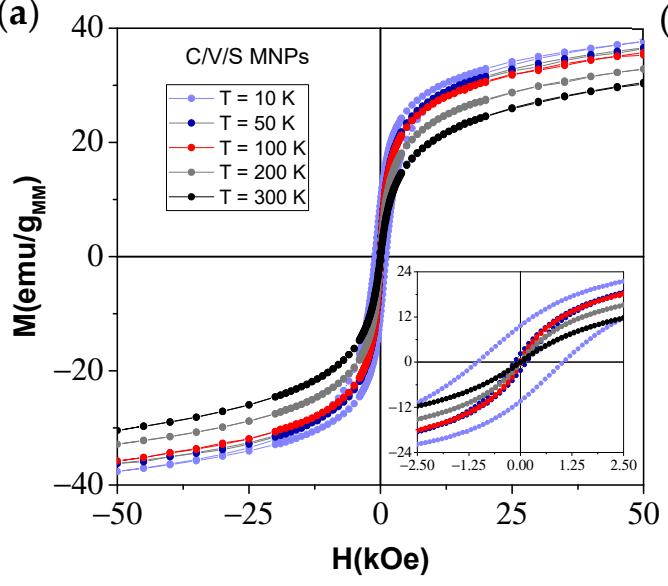

(b)

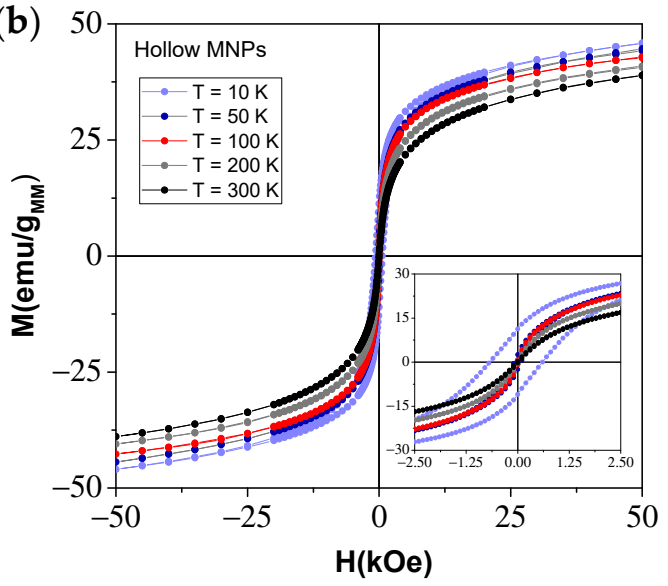

Figure 4. Hysteresis loops of (a) core/void/shell MNPs and (b) hollow iron oxide MNPs at different temperatures: 10, 50, 100, 200 and 300 K. Insets: Scale amplification of hysteresis loops.

Maximum magnetization values at $\mathrm{H}=50 \mathrm{kOe}$ between $38.17(10 \mathrm{~K})$ and $30.75(300 \mathrm{~K})$ emu/g and $45.93(10 \mathrm{~K})$ and $38.90(300 \mathrm{~K}) \mathrm{emu} / \mathrm{g}$ were obtained for the $\mathrm{C} / \mathrm{V} / \mathrm{S}$ and hollow MNPs, respectively. Lower values of magnetization were observed in C/V/S MNPs due to lower crystallinity than in hollow MNPs. However, the magnetization values did not differ too much between both MNPs. This agrees with the XRD results, from which it can be concluded that the $\mathrm{C} / \mathrm{V} / \mathrm{S}$ were in an intermediate state of crystallinity prior to the formation of hollow MNPs. Despite the high values of the S/V ratio, the magnetization was not drastically reduced by surface effects. This suggests that hollow MNPs may emerge as an interesting alternative, presenting improved magnetic properties and exhibiting an intrinsic EB effect.

\subsection{Exchange Bias Properties}

In order to study the EB and spin disorder properties, the magnetization of the specimens as a function of magnetic field and temperature was measured under FC, using 11 different cooling fields (0.1-50 kOe) and ZFC conditions. All the hysteresis loops were performed using the same measuring field (between $-50 \mathrm{kOe}$ and $50 \mathrm{kOe}$ ). Figure 5 shows hysteresis loops with ZFC conditions (black points) and with $\mathrm{H}_{\mathrm{FC}}=10 \mathrm{kOe}$ (red points) for $\mathrm{C} / \mathrm{V} / \mathrm{S}$ MNPs (Figure 5a) and for hollow MNPs (Figure $5 \mathrm{~b}$ ) at $5 \mathrm{~K}$. A shift of the hysteresis loops toward both the negative field and the positive magnetization axis is observed, which, with an enhanced coercive field $\left(\mathrm{H}_{\mathrm{C}}{ }^{\mathrm{ZFC}}=1099 \mathrm{Oe}\right.$ and $\mathrm{H}_{\mathrm{C}}{ }^{\mathrm{FC}}=10 \mathrm{kOe}=1515 \mathrm{Oe}$ of $\mathrm{C} / \mathrm{V} / \mathrm{S}$ and $\mathrm{H}_{\mathrm{C}}{ }^{\mathrm{ZFC}}=601 \mathrm{Oe}$ and $\mathrm{H}_{\mathrm{C}}{ }^{\mathrm{FC}=10 \mathrm{kOe}}=636$ Oe of hollow MNPs), constitutes strong evidence of the existence of an exchange bias effect [8,9].

In order to study the oleylamine coating effect of the $\mathrm{C} / \mathrm{V} / \mathrm{S}$ and hollow MNPs on reducing the direct interactions between MNPs, iron oxide solid MNPs of similar sizes and with an oleylamine coating were studied under FC conditions. Figure S2 shows a comparison between the hysteresis loops of the solid iron oxide MNPs (black points) and hollow MNPs (red points) under FC conditions $\left(\mathrm{H}_{\mathrm{FC}}=10 \mathrm{kOe}\right)$ at $5 \mathrm{~K}$. No EB effect on iron oxide solid MNPs was observed, suggesting that exchange interactions between MNPs are prevented with the oleylamine shell. Therefore, the effect of the interactions between MNPs in EB generation was satisfactorily avoided using a functional coating.

Figure 6a shows the $\mathrm{H}_{\mathrm{EB}}$ dependence with $\mathrm{H}_{\mathrm{FC}}$. In comparison, the $\mathrm{C} / \mathrm{V} / \mathrm{S} \mathrm{MNPs}$ exhibited a higher maximum $\mathrm{H}_{\mathrm{EB}}\left(\mathrm{H}_{\mathrm{EB}}=581.5 \mathrm{Oe}\right)$ than the hollow MNPs $\left(\mathrm{H}_{\mathrm{EB}}=444.0 \mathrm{Oe}\right)$. In addition, the maximum $\mathrm{H}_{\mathrm{EB}}$ values were obtained at different cooling fields, $\mathrm{H}_{\mathrm{FC}}=5 \mathrm{kOe}$ for $\mathrm{C} / \mathrm{V} / \mathrm{S}$ MNPs and $\mathrm{H}_{\mathrm{FC}}=3 \mathrm{kOe}$ for hollow MNPs. In both MNPs, it was observed that the $\mathrm{H}_{\mathrm{EB}}$ maximum was not reached in the largest applied cooling field $\left(\mathrm{H}_{\mathrm{FC}}=50 \mathrm{kOe}\right)$, showing a maximum field below which $\mathrm{H}_{\mathrm{EB}}$ decays. This trend was not observed in previous studies based on $\mathrm{Fe} / \mathrm{Fe}_{3} \mathrm{O}_{4}$ MNPs of $13.8 \mathrm{~nm}$, in which studies of the $\mathrm{H}_{\mathrm{EB}}$ dependence with $\mathrm{H}_{\mathrm{FC}}$ were carried out up to $\mathrm{H}_{\mathrm{FC}}=10 \mathrm{kOe}$ [33]. In our case, this new trend was 
observed by investigating the $\mathrm{H}_{\mathrm{EB}}$ behavior with cooling fields greater than $10 \mathrm{kOe}$ (up to $50 \mathrm{kOe}$ ). In addition, the trend of $\mathrm{H}_{\mathrm{EB}}$ with $\mathrm{H}_{\mathrm{FC}}$ has not been reported in hollow MNPs due to the low value of $\mathrm{H}_{\mathrm{EB}}$ [23]. Therefore, to our knowledge, the present study suggests a new trend of $\mathrm{H}_{\mathrm{EB}}$ with $\mathrm{H}_{\mathrm{FC}}$ in hollow iron oxide MNPs not reported so far.

(a)

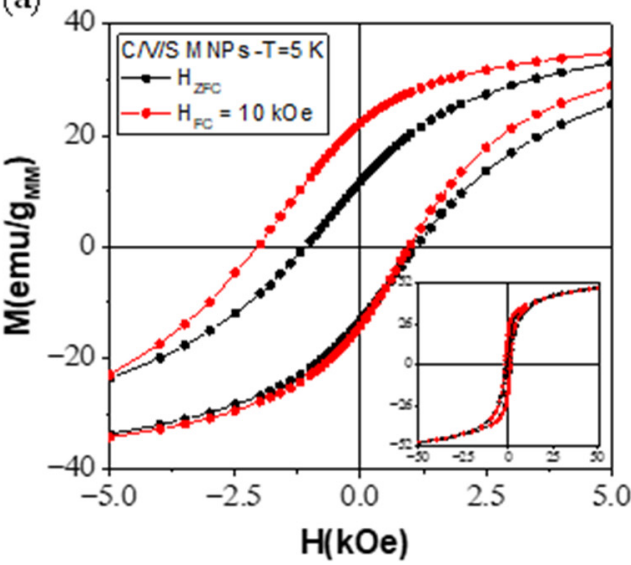

(b)

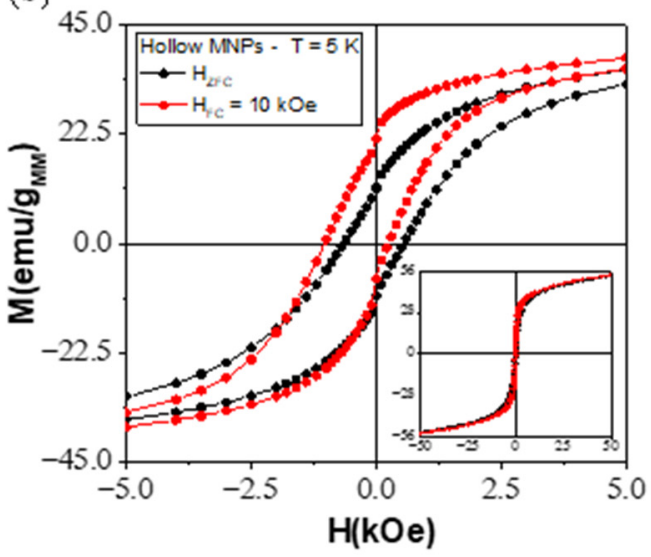

Figure 5. Hysteresis loops of (a) core/void/shell MNPs and (b) iron oxide hollow MNPs at $5 \mathrm{~K}$ cooled without field (ZFC, black points) and with $\mathrm{H}_{\mathrm{FC}}=10 \mathrm{kOe}$ (FC, red points) in the range of $-50 \mathrm{kOe}$ and $50 \mathrm{kOe}$. For clarity only the range between $-5 \mathrm{kOe}$ and $5 \mathrm{kOe}$ is shown. Insets: Complete hysteresis loops. A hysteresis loop shift is observed in both $\mathrm{X}$ (field) and $\mathrm{Y}$ (magnetization) axes, indicating the presence of EB.
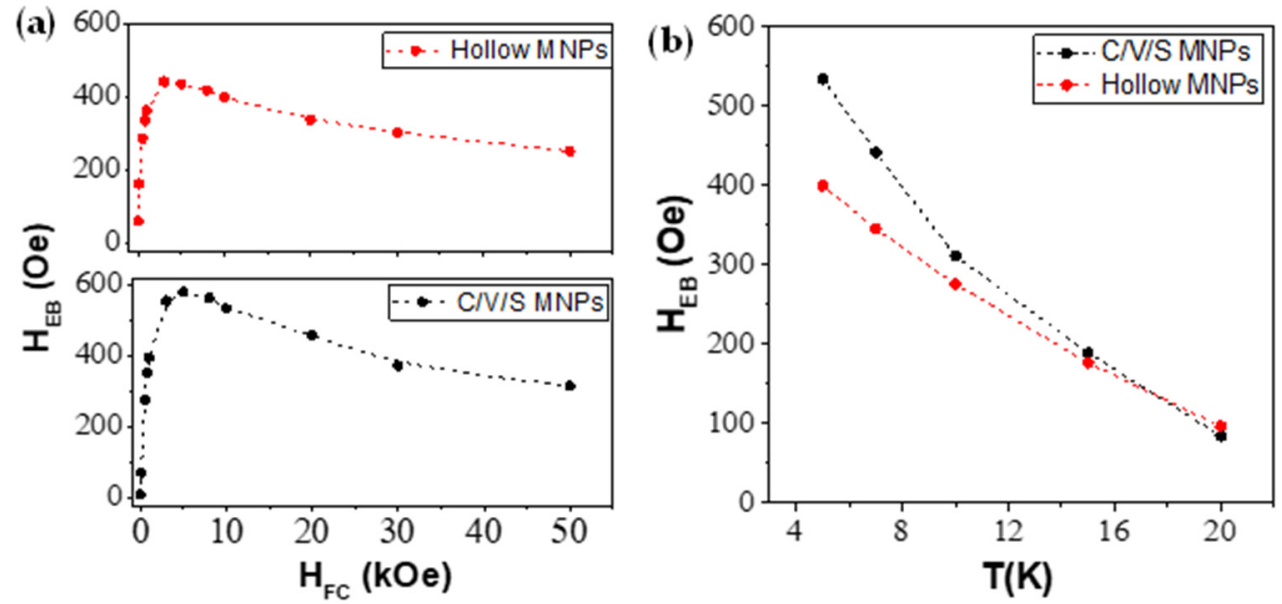

Figure 6. (a) Exchange bias field $\left(\mathrm{H}_{\mathrm{EB}}\right)$ measured at $5 \mathrm{~K}$ for core/void/shell (black dots) and hollow MNPs (red dots) as a function of the cooling fields $\left(\mathrm{H}_{\mathrm{FC}}\right)$. (b) Exchange bias field $\left(\mathrm{H}_{\mathrm{EB}}\right)$ for core/void/shell (black dots) and hollow MNPs (red dots) as a function of the temperature $(\mathrm{T}=5-20 \mathrm{~K})$.

Since EB is a phenomenon that occurs at low temperatures, the temperature dependence must be studied. Accordingly, magnetic measurements under FC conditions were carried out using a $\mathrm{H}_{\mathrm{FC}}=10 \mathrm{kOe}$ and different temperatures, 5, 7, 10, 15, and $20 \mathrm{~K}$. Figure $6 \mathrm{~b}$ shows the $\mathrm{H}_{\mathrm{EB}}$ dependence with temperature of $\mathrm{C} / \mathrm{V} / \mathrm{S}$ MNPs (black points) and hollow MNPs (red points). Both MNPs show a decrease in $\mathrm{H}_{\mathrm{EB}}$ with temperature from the corresponding maximum values at $5 \mathrm{~K}$ (534.5 Oe for C/V/S and 400.0 Oe for hollow MNPs with $\mathrm{H}_{\mathrm{FC}}=10 \mathrm{kOe}$ ) to an approximate value of $100 \mathrm{Oe}$ at $20 \mathrm{~K}$. This shows that although $\mathrm{H}_{\mathrm{EB}}$ is produced below the Néel temperature, the $\mathrm{H}_{\mathrm{EB}}$ is drastically reduced with increasing temperature. 
It has been reported that the morphology of MNPs plays an important role in EB generation. In core/shell MPNs, an exchange coupling between the core and shell components has been reported. A hysteresis loop shift has been observed in core/shell $\mathrm{FeO} / \mathrm{Fe}_{3} \mathrm{O}_{4}$ MNPs with sizes between 10 and $35 \mathrm{~nm}$ and with surface-to-volume ratios between 0.60 and 0.17 [26,29-31]. In this case, the core features antiferromagnetic properties, while the shell features ferrimagnetic properties. As can be seen in Table 2, a direct relationship between the size of the particles and the $\mathrm{H}_{\mathrm{EB}}$ value was not observed. Interestingly, an EB phenomenon was obtained in MNPs as large as $35 \mathrm{~nm}$. This shows that EB is generated by the core-shell coupling because the size of the $\mathrm{FeO} / \mathrm{Fe}_{3} \mathrm{O}_{4} \mathrm{MNPs}$ is sufficiently high for the surface effects to not be noticeable. In addition, EB was reported in MNPs formed by a non-oxidized Fe core (ferromagnetic) and an $\mathrm{Fe}_{3} \mathrm{O}_{4}$ shell (ferrimagnetic) with $\mathrm{D}_{\mathrm{T}}=14 \mathrm{~nm}$ and $\delta_{\mathrm{S}}=2.5 \mathrm{~nm}$ [23]. Even though all these MNPs feature large $\mathrm{H}_{\mathrm{EB}}$ values and EB generation is dominated by the core-shell, the transformation in hollow MNPs has not been studied. Therefore, core/void/shell MNPs formed prior to hollow MNP formation should be studied to better understand EB generation. These MNPs are formed by three surface layers, corresponding to the shell and the core. This leads to a higher surface-to-volume ratio and surface effects begin to play an important role. For this reason, it is important to note that the core/void/shell MNPs presented here feature a much higher surface-to-volume ratio (0.9) than the $\mathrm{Fe} / \mathrm{Fe}_{3} \mathrm{O}_{4} \mathrm{MNPs}$ shown in Table 2, even those with a smaller size $\left(\mathrm{FeO} / \mathrm{Fe}_{3} \mathrm{O}_{4} \mathrm{MNPs}\right.$ of $10 \mathrm{~nm}$ with $\left.\mathrm{S} / \mathrm{V}=0.6\right)$.

Table 2. Total diameter $\left(\mathrm{D}_{\mathrm{T}}\right)$, shell thickness $\left(\delta_{\mathrm{S}}\right)$, hysteresis loop shift $\left(\mathrm{H}_{\mathrm{EB}}\right)$, and surface-to-volume ratio(S/V) values of iron oxide-based core/shell MNPs.

\begin{tabular}{ccccccc}
\hline Core/Shell & Void? & $\mathbf{d}_{\mathbf{T}}(\mathbf{n m})$ & $\boldsymbol{\delta}_{\mathbf{S}}(\mathbf{n m})$ & $\mathbf{H}_{\mathbf{E B}}(\mathbf{O e})$ & $\mathbf{S} / \mathbf{V}$ & Ref \\
\hline $\mathrm{FeO} / \mathrm{Fe}_{3} \mathrm{O}_{4}$ & $\mathrm{No}$ & 10.1 & 0.6 & 1700 & 0.60 & {$[26]$} \\
\hline $\mathrm{FeO} / \mathrm{Fe}_{3} \mathrm{O}_{4}$ & $\mathrm{No}$ & 14 & 3.5 & 471 & 0.43 & {$[31]$} \\
\hline $\mathrm{FeO} / \mathrm{Fe}_{3} \mathrm{O}_{4}$ & $\mathrm{No}$ & 18 & $\sim 6$ & $\sim 1000$ & 0.33 & {$[46]$} \\
\hline $\mathrm{FeO} / \mathrm{Fe}_{3} \mathrm{O}_{4}$ & $\mathrm{No}$ & 35 & 4 & 2260 & 0.17 & {$[30]$} \\
\hline $\mathrm{Fe} / \mathrm{Fe}_{3} \mathrm{O}_{4}$ & $\mathrm{No}$ & 13.8 & 2.5 & 1190 & 0.43 & {$[23]$} \\
\hline $\mathrm{C} / \mathrm{V} / \mathrm{S} \mathrm{MNPs}$ & $\mathrm{Yes}$ & 11.9 & 2.4 & 581.5 & 0.9 & Present Study \\
\hline
\end{tabular}

The hollow MNPs were only studied after the Fe core oxidation in the precursor $\mathrm{C} / \mathrm{V} / \mathrm{S}$ MNPs. However, the $\mathrm{H}_{\mathrm{EB}}$ values obtained were significantly low and a study on the EB properties in C/V/S MNPs was not carried out. In addition, the $\mathrm{H}_{\mathrm{EB}}$ value observed in these hollow MNPs is practically negligible [23,33] Here, a study of the EB effect in core/void/shell MNPs was carried out to understand which mechanisms affect EB generation in hollow MNPs.

On the other hand, a hysteresis loop shift in hollow $\gamma-\mathrm{Fe}_{2} \mathrm{O}_{3} \mathrm{MNPs}$ (either a minor loop or an intrinsic EB effect) was reported (Table 3). The $\gamma-\mathrm{Fe}_{2} \mathrm{O}_{3} \mathrm{MNPs}$ with a total diameter of $\mathrm{D}_{\mathrm{T}}=8.1 \mathrm{~nm}$ and shell thickness of $\delta_{\mathrm{S}}=1.6 \mathrm{~nm}$ showed a high hysteresis loop shift of 3000 Oe. However, since the maximum applied field is smaller than the irreversibility field, this shift is a minor loop and not an EB effect [37]. Similar behavior was reported in the $\gamma-\mathrm{Fe}_{2} \mathrm{O}_{3} \mathrm{MNPs}$ with $\mathrm{D}_{\mathrm{T}}=9.2 \mathrm{~nm}$ and $\delta_{\mathrm{S}}=2 \mathrm{~nm}$. In this case, the hysteresis loop shift was attributed to the high number of disoriented spins on the shell surface and at the interfaces of the crystallographic domains [34]. Furthermore, a minor loop effect was also observed in the $\gamma-\mathrm{Fe}_{2} \mathrm{O}_{3} \mathrm{MNPS}$ with $\mathrm{D}_{\mathrm{T}}=9.4 \mathrm{~nm}$ and $\delta_{\mathrm{S}}=1.9 \mathrm{~nm}$ [32]. These three systems, with similar sizes and shell thicknesses, show that in smaller hollow MNPs, in which there is a greater number of disordered spins on the surface than in larger hollow systems, the hysteresis loops shift corresponds to a minor loop effect and not a EB phenomenon. A minor loop effect has also been reported in $\gamma-\mathrm{Fe}_{2} \mathrm{O}_{3} \mathrm{MNPs}$ with a larger size $\left(\mathrm{D}_{\mathrm{T}}=14.7 \mathrm{~nm}\right.$ and $\delta_{\mathrm{S}}=3.2 \mathrm{~nm}$ ). In addition, due to surface effects, all these MNPs present low magnetization values. 
Table 3. Total diameter $\left(\mathrm{D}_{\mathrm{T}}\right)$, shell thickness $\left(\delta_{\mathrm{S}}\right)$, hysteresis loop shift values $\left(\mathrm{H}_{\mathrm{EB}}\right)$, type of hysteresis loop shift, and surface-to-volume ratio (S/V) of iron-oxide-based hollow MNPs.

\begin{tabular}{ccccccc}
\hline Hollow & $\mathbf{d}_{\mathbf{T}}(\mathbf{n m})$ & $\begin{array}{c}\boldsymbol{\delta}_{\mathbf{S}} \\
(\mathbf{n m})\end{array}$ & $\mathbf{H}_{\mathbf{E B}}(\mathbf{O e})$ & Type & $\mathbf{S} / \mathbf{V}$ & Ref \\
\hline$\gamma-\mathrm{Fe}_{2} \mathrm{O}_{3}$ & 8.1 & 1.6 & $\sim 3000$ & Minor Loop & 1.29 & {$[37]$} \\
\hline$\gamma-\mathrm{Fe}_{2} \mathrm{O}_{3}$ & 9.2 & 2 & - & Minor Loop & 1.05 & {$[34]$} \\
\hline$\gamma-\mathrm{Fe}_{2} \mathrm{O}_{3}$ & 9.4 & 1.9 & $\sim 5000$ & Minor Loop & 1.10 & {$[32]$} \\
\hline$\gamma-\mathrm{Fe}_{2} \mathrm{O}_{3}$ & 14.7 & 3.2 & $\sim 7000$ & Minor Loop & 0.66 & {$[32]$} \\
\hline$\gamma-\mathrm{Fe}_{2} \mathrm{O}_{3}$ & 18.7 & 4.5 & 960 & EB & 0.47 & {$[34]$} \\
\hline $\mathrm{Fe}_{3} \mathrm{O}_{4}$ & 16.0 & 4.5 & 133 & EB & 0.49 & {$[23]$} \\
\hline Iron Oxide & 13.2 & 3.7 & 444 & EB & 0.6 & Present Study \\
\hline
\end{tabular}

In this work, iron oxide-based hollow MNPs with $\mathrm{D}_{\mathrm{T}}=13.2 \mathrm{~nm}$ and $\delta_{\mathrm{S}}=4.5 \mathrm{~nm}$ and with surface-to-volume values of 0.6 are presented, showing an intrinsic EB phenomenon with enhanced magnetization. To this end, a complete study of the role played by interfacial and surface spins in the EB generation must be carried out both in hollow MNPs and in the precursor $\mathrm{C} / \mathrm{V} / \mathrm{S}$ MNPS prior to the complete oxidation of the Fe core.

\subsection{Role of Surface Spins}

In order to determine the role of surface spins in the magnetic properties of MNPs, the superparamagnetic (SPM) and paramagnetic (PM) contributions of the MNPs were studied. The experimental data are fitted according to the Langevin function with an added linear term corresponding to the PM contribution:

$$
\mathrm{M}(\mathrm{H})=\mathrm{M}_{\mathrm{S}}^{\mathrm{SPM}}\left[\operatorname{coth}\left(\frac{\mu \mathrm{H}}{\mathrm{K}_{\mathrm{B}} \mathrm{T}}\right)-\left(\frac{\mu \mathrm{H}}{\mathrm{K}_{\mathrm{B}} \mathrm{T}}\right)^{-1}\right]+\mathrm{C}^{\mathrm{PM}} \mathrm{H}
$$

where $\mathrm{M}_{\mathrm{S}}{ }^{\mathrm{SPM}}$ is the saturation magnetization of the SPM component, $\mu$ is the average magnetic moment of the MNPs, $\mathrm{C}^{\mathrm{PM}}$ is the susceptibility of the paramagnetic contribution, and $\mathrm{H}$ is the magnetic field. Figure $7 \mathrm{a}, \mathrm{b}$ shows the initial magnetization at $300 \mathrm{~K}$ of $\mathrm{C} / \mathrm{V} / \mathrm{S}$ and hollow MNPs, respectively.
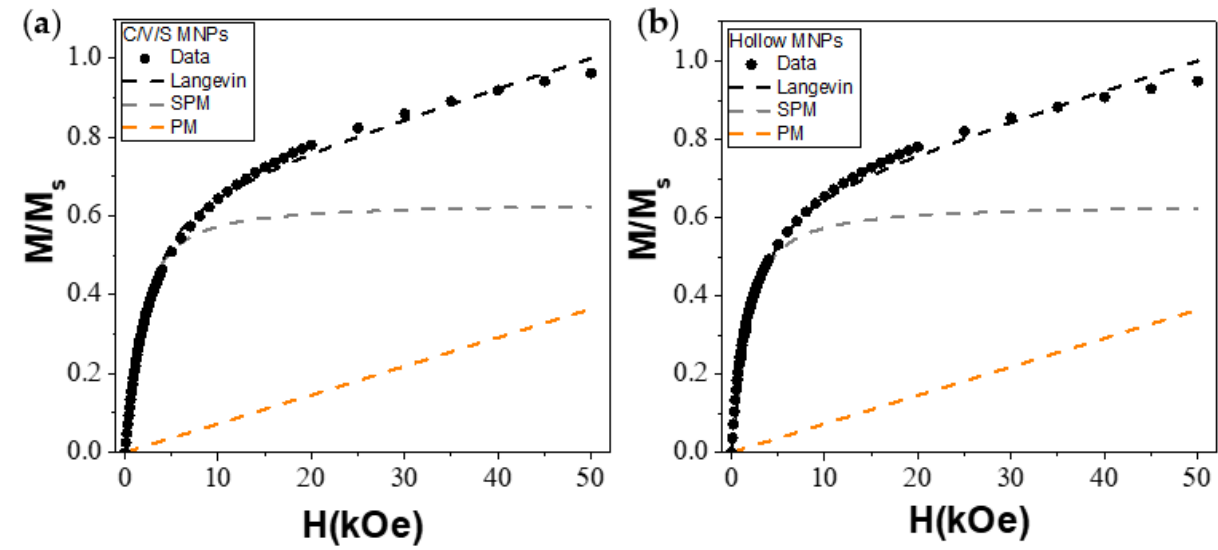

Figure 7. Initial magnetization curve at $300 \mathrm{~K}$ of (a) core/void/shell and (b) hollow iron oxide MNPs fitted to Equation (3). The black, gray, and orange dashed curves represent the Langevin fit and the SPM and PM contributions, respectively.

As can be seen from the experimental data (black points) and the Langevin fit (black dashed line) of the C/V/S and hollow MNPs, respectively, the SPM contribution (gray dashed line), corresponding to the inner spins, and the PM contribution (orange dashed 
line), corresponding to the surface spins, were obtained. From these fits, SPM contributions of 76 and $73 \%$ for C/V/S and hollow MNPs, respectively, were obtained. On the other hand, PM contributions represented $23 \%$ and $26 \%$ for C/V/S and hollow MNPs, respectively.

From these results, it is possible to conclude that a significant number of surface spins in both MNPs play an important role in the magnetic properties. In turn, the greater number of surface spins present in the hollow MNPs (26\%) may be due to the larger shell size of the hollow MNPs. At low temperatures, these spins may enter a spin-glass-like state, whose exchange coupling with the ordered spins generates an EB effect. The spinglass-like behavior was inferred from the AC measurements by the $\Phi$ parameter. Values of $\Phi$ below 0.06 demonstrate spin-glass-like behavior in MNPs [32]. Values of 0.04 and 0.05 were obtained for the core/void/shell and hollow MNPs, respectively, showing spin-glass behavior (See Supporting Information).

However, the higher surface-to-volume ratio of the $\mathrm{C} / \mathrm{V} / \mathrm{S}(\mathrm{S} / \mathrm{V}=0.9)$ compared to the hollow MNPs $(S / V=0.6)$ indicates a greater surface area due to the additional surface area of the Fe core. This suggests the greater role of the surface spins located in the shell in the magnetic properties of the MNPs than the role of the surface spins located in the Fe core, which were negligible. Based on the surface area of the inner and outer surfaces of the hollow MNPs, an estimation of the \% of surface spins corresponding to each surface was carried out. Values of 21.8 and $4.2 \%$ for the external and internal surface spins, respectively, were obtained in the hollow MNPs, showing the significant contribution of the surface spins of the external layer. In addition, the effect of the inner surface spins was studied by comparing the EB phenomenon in the solid and hollow MNPs. Figure S2 shows a comparison between the hysteresis loops of the solid iron oxide MNPs (black points) and the hollow MNPs (red points) under FC conditions $\left(\mathrm{H}_{\mathrm{FC}}=10 \mathrm{kOe}\right)$ at $5 \mathrm{~K}$. A significant reduction in the PM contribution was observed in the solid MNPs. Considering the similar amount of surface spins in the external layer in both MNPs, the importance of the additional internal surface spin layer in the magnetic properties and in the EB generation was demonstrated. Although H. Khurshid et al. [34] have discussed the effect of surface internal spins in this way, the multiple phenomena in EB generation, such as the exchange coupling of frozen spins from internal nanograins, do not allow a clear differentiation between the internal and external spins' contribution in EB. Therefore, more experimental studies must be carried out.

In a similar study, the contribution of the SPM and PM components was obtained in $9.2 \mathrm{~nm}$ and $18.7 \mathrm{~nm} \gamma-\mathrm{Fe}_{2} \mathrm{O}_{3}$ hollow MNPs. In this case, PM contributions of $87 \%(9.2 \mathrm{~nm})$ and $3 \%(18.7 \mathrm{~nm})$ were obtained. An increase in the linear component of magnetization (and a greater number of surface spins) was demonstrated due to the reduction in the thickness of the shell [34]. For this reason, a lower PM contribution was observed on the magnetic properties of $\mathrm{Fe} / \mathrm{Fe}_{3} \mathrm{O}_{4} \mathrm{MNPs}$ and hollow $\mathrm{Fe}_{3} \mathrm{O}_{4} \mathrm{MNPs}$ of 13.8 and $16.0 \mathrm{~nm}$, respectively, by Ong et al. [33] than in our MNPs of smaller sizes (11.9 nm for C/V/S and $13.2 \mathrm{~nm}$ for hollow MNPs). Thus, the significantly lower values obtained in the $16.0 \mathrm{~nm}$ hollow $\mathrm{Fe}_{3} \mathrm{O}_{4} \mathrm{MNPs}\left(\mathrm{H}_{\mathrm{EB}}=133 \mathrm{Oe}\right)$ than in our hollow MNPs $\left(\mathrm{H}_{\mathrm{EB}}=444 \mathrm{Oe}\right)$ highlight the importance of surface spins to the improvement the EB properties of hollow iron oxide MNPs.

\subsection{Remanence $\left(M_{R}\right)$ and Coercivity $\left(H_{C}\right)$ Dependence with Cooling Field $\left(H_{F C}\right)$}

A study of the remanence $\left(M_{R}\right)$ and coercive force $\left(H_{C}\right)$ dependence with $H_{F C}$ was carried out with the aim of understanding the EB generation process. Figure 8a shows the $\mathrm{M}_{\mathrm{R}}$ dependence with $\mathrm{H}_{\mathrm{FC}}$ of the $\mathrm{C} / \mathrm{V} / \mathrm{S}$ MNPs (black dots) and hollow MNPs (red dots). For small fields, $\mathrm{M}_{\mathrm{R}}$ increases with $\mathrm{H}_{\mathrm{FC}}$. However, from $\mathrm{H}_{\mathrm{FC}} \geq 20 \mathrm{kOe}$, a maximum value was reached, and $M_{R}$ remained constant. This indicates that the sample retained more magnetization by increasing $\mathrm{H}_{\mathrm{FC}}$. Figure $8 \mathrm{~b}$ shows the $\mathrm{H}_{\mathrm{C}}$ dependence with $\mathrm{H}_{\mathrm{FC}}$ of $\mathrm{C} / \mathrm{V} / \mathrm{S}$ MNPs (black dots) and hollow MNPs (red dots). Similarly to $\mathrm{M}_{\mathrm{R}}$, a steep rise in $\mathrm{H}_{C}$ along with increasing $\mathrm{H}_{\mathrm{FC}}$ from low values was observed. Next, a maximum value of $\mathrm{H}_{\mathrm{C}}$ was 
reached, followed by a decrease for larger $\mathrm{H}_{\mathrm{FC}}$. The maximum $\mathrm{H}_{\mathrm{C}}$ was reached at different $\mathrm{H}_{\mathrm{FC}}$ for each MNP: $5 \mathrm{kOe}$ for the C/V/S MNPs and $3 \mathrm{kOe}$ for the hollow MNs.
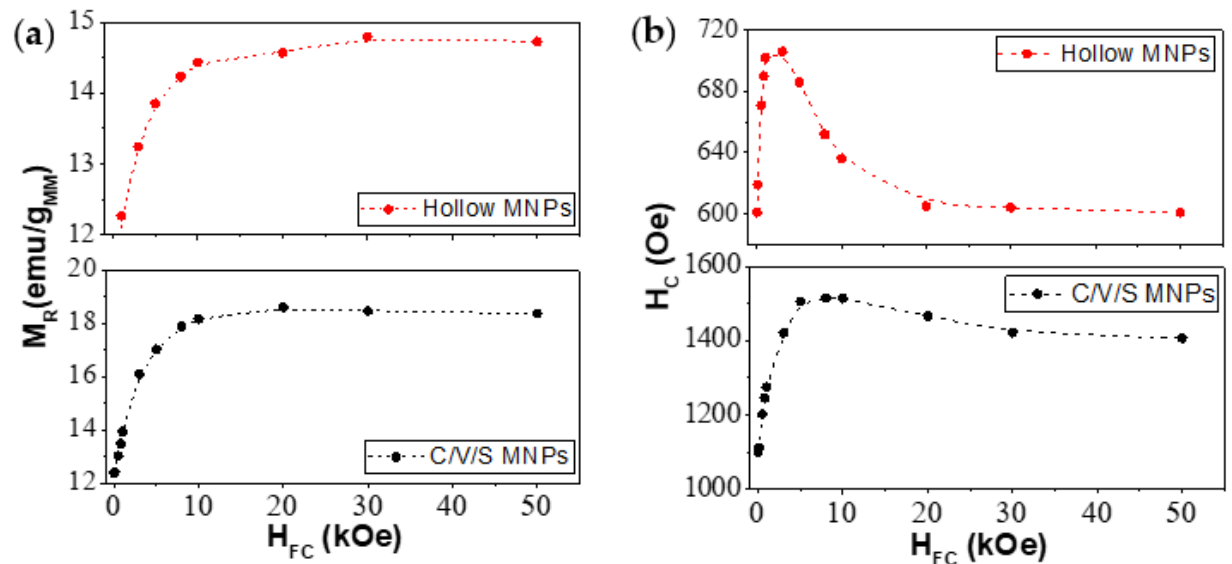

Figure 8. (a) Remanent magnetization $\left(\mathrm{M}_{\mathrm{R}}\right)$ and $(\mathbf{b})$ coercivity $\left(\mathrm{H}_{\mathrm{C}}\right)$ measured at $5 \mathrm{~K}$ for core/void/shell (black dots) and hollow MNPs (red dots) as a function of the cooling field $\left(\mathrm{H}_{\mathrm{FC}}\right)$.

Two different regions were observed in the $\mathrm{M}_{\mathrm{R}}, \mathrm{H}_{\mathrm{C}}$, and $\mathrm{H}_{\mathrm{EB}}$ dependence with $\mathrm{H}_{\mathrm{FC}}$. In the first region, for low $\mathrm{H}_{\mathrm{FC}}$, where $\mathrm{M}_{\mathrm{R}}, \mathrm{H}_{\mathrm{C}}$, and $\mathrm{H}_{\mathrm{EB}}$ increase with $\mathrm{H}_{\mathrm{FC}}$. A preferential direction, along which the magnetic moments tended to freeze at $5 \mathrm{~K}$, was induced by the cooling field. Therefore, the exchange anisotropy was not averaged out (as in ZFC conditions) and a net exchange bias effect was observed. However, for high $\mathrm{H}_{\mathrm{FC}}$, the coupling between the magnetic moments and the $\mathrm{H}_{\mathrm{FC}}$ (Zeeman coupling) was no longer negligible compared to the exchange coupling existing in the MNPs. Thus, the energy associated with the exchange interactions was not minimized due to Zeeman coupling, generating a decrease in $\mathrm{H}_{C}$ and $\mathrm{H}_{\mathrm{EB}}$ [42]. This Zeeman coupling was greater as $\mathrm{H}_{\mathrm{FC}}$ increased. It can be seen how the maximum of $\mathrm{H}_{\mathrm{EB}}$ was different in both MNPs, suggesting that the Zeeman coupling begins to be noticeable at lower $\mathrm{H}_{\mathrm{FC}}$ in hollow MNPs. In the hollow MNPs, the first region in which $\mathrm{M}_{\mathrm{R}}, \mathrm{H}_{\mathrm{C}}$, and $\mathrm{H}_{\mathrm{EB}}$ increased with $\mathrm{H}_{\mathrm{FC}}$ was produced for $\mathrm{H}_{\mathrm{FC}}<3 \mathrm{kOe}$ and in the $\mathrm{C} / \mathrm{V} / \mathrm{S}$ MNPs for $\mathrm{H}_{\mathrm{FC}}<5 \mathrm{kOe}$. This suggests that the effect of averaging of the anisotropy, due to randomness, was more reduced in the $\mathrm{C} / \mathrm{V} / \mathrm{S}$ than in the hollow MNPs.

\subsection{Frozen Spins Behavior}

In order to understand the behavior of the exchange coupling in both MNPs and their dependence on $\mathrm{H}_{\mathrm{FC}}$, a study of the number of frozen spins in the MNPs was carried out. A vertical shift in the hysteresis loop under FC conditions in the direction of the cooling field is proportional to the number of frozen spins that cannot be reversed by the measurement field [53]. The net moment of frozen spins can be quantified as:

$$
\mathrm{M}_{\mathrm{f}}=\frac{1}{2}\left[\mathrm{M}\left(\mathrm{H}^{+}\right)-\mathrm{M}\left(\mathrm{H}^{-}\right)\right]
$$

Here the positive direction is the direction of the cooling field. $\mathrm{M}_{\mathrm{f}}$ studies were carried out using different $\mathrm{H}_{\mathrm{FC}}$ and different temperatures of both $\mathrm{C} / \mathrm{V} / \mathrm{S}$ and hollow MNPs to understand the role of frozen spins in the EB generation.

Figure 9a shows the relative magnitude of the frozen moment $\left(\mathrm{M}_{\mathrm{f}} / \mathrm{M}\left(\mathrm{H}^{+}\right)\right)$for the C/V/S MNPs (black points) and hollow MNPs (red points). Similar trends in both MNPs were observed. The number of frozen spins showed a drastic increase as the value of the cooling field increased. Subsequently, the number of spins reached a maximum value that did not correspond to the $\mathrm{H}_{\mathrm{FC}}$. Once this maximum was reached, the number of frozen spins began to decrease. This fact indicates that the irreversible spins began to reverse their moment due to the high magnetic field applied. This fact agrees with the trends observed 
for $\mathrm{H}_{\mathrm{C}}$ and $\mathrm{H}_{\mathrm{EB}}$, whose values reached a maximum due to the Zeeman coupling. The $\mathrm{M}_{\mathrm{f}} / \mathrm{M}\left(\mathrm{H}^{+}\right)$maximum was $18 \%$ (for $\mathrm{H}_{\mathrm{FC}}=10 \mathrm{kOe}$ ) and $34 \%$ (for $\mathrm{H}_{\mathrm{FC}}=8 \mathrm{kOe}$ ) for the $\mathrm{C} / \mathrm{V} / \mathrm{S}$ MNPs and hollow MNPs, respectively, demonstrating the presence of exchange coupling in both MNPs. The core/void/shell MNPs did not present a direct exchange coupling, but rather discontinuously, due to the presence of gaps between the core and the shell; it must be considered that exchange coupling is a short-range interaction and decays exponentially with distance [33]. However, exchange interactions between the Fe core and the iron oxide shell cannot be totally ruled out. On the other hand, the hollow MNPs did not present said Fe core and the presence of frozen spins cannot be explained in this way. This result, together with the HRTEM images, allows us to show that the shell of the C/V/S and the hollow MNPs was formed by nanograins that were coupled to each other. This coupling was, in part, responsible of the EB generation in the hollow MNPs and it is presented as an alternative to classic EB generation, which is produced by two magnetically different materials. The higher number of frozen spins in the hollow MNPs may have been due to the larger size of the shell (3.7 nm for the hollow MNPs and $2.4 \mathrm{~nm}$ for the C/V/S MNPs) and, therefore, of the nanograins that formed the shell. In addition, the presence of the Fe core in the C/V/S MNPs formed by reversible spins must be considered. This number of reversible spins present in the Fe core could counteract the frozen spins in C/V/S MNPs and, therefore, the percentage of frozen spins in C/V/S MNPs was lower.
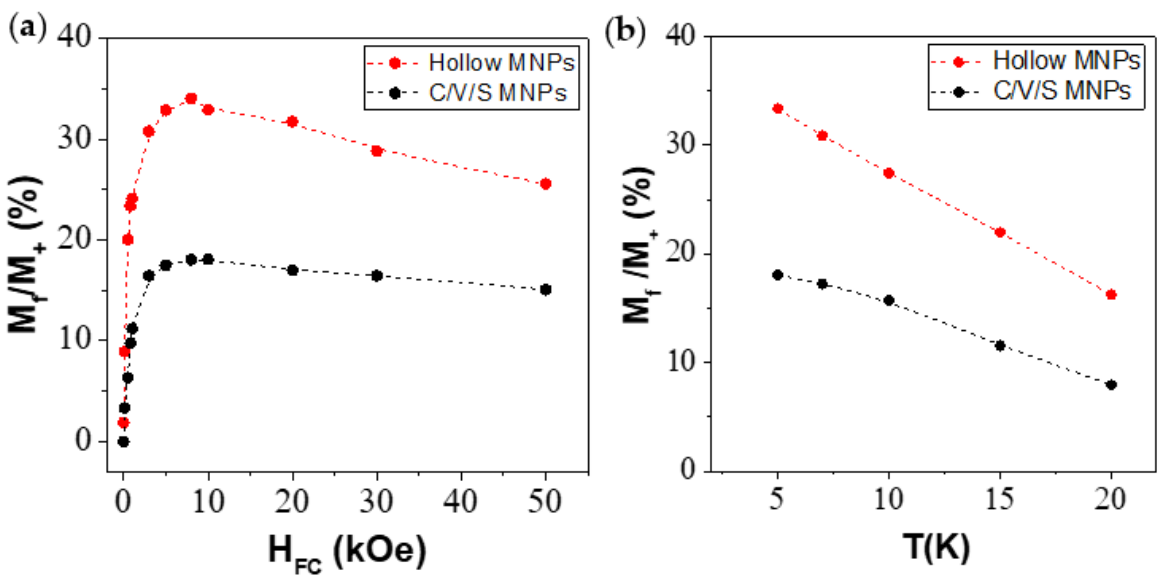

Figure 9. (a) Relative magnitude of frozen moment $\left(\mathrm{M}_{\mathrm{f}} / \mathrm{M}\left(\mathrm{H}^{+}\right)\right)$measured at $5 \mathrm{~K}$ for $\mathrm{C} / \mathrm{V} / \mathrm{S}$ (black dots) and hollow MNPs (red dots) as a function of the cooling field $\left(\mathrm{H}_{\mathrm{FC}}\right)$. (b) Relative magnitude of frozen moment $\left(\mathrm{M}_{\mathrm{f}} / \mathrm{M}\left(\mathrm{H}^{+}\right)\right)$) for $\mathrm{C} / \mathrm{V} / \mathrm{S}$ (black dots) and hollow MNPs (red dots) as a function of the temperature $(\mathrm{T}=5-20 \mathrm{~K})$.

Figure $9 \mathrm{~b}$ shows the temperature dependence of $\left(\mathrm{M}_{\mathrm{f}} / \mathrm{M}\left(\mathrm{H}^{+}\right)\right)$for the $\mathrm{C} / \mathrm{V} / \mathrm{S}$ MNPs (red points) and hollow MNPs (black points). In the hollow MNPs, a decrease from 33 to $16 \%$ was observed when the temperature increased from 5 to $20 \mathrm{~K}$. On the other hand, the C/V/S MNPs showed a decrease from 18 to $8 \%$ at the same temperatures. This decrease was also observed in $\mathrm{H}_{\mathrm{EB}}$, showing the importance of interfacial spins in EB generation.

Based on these results, a spin distribution for both MNPs is proposed, with the aim of shedding light on EB generation. Figure 10 shows a diagram of the spin distribution of (a) C/V /S and (b) hollow MNPs. The presence of two layers of surface spin in the shells of the MNPs is suggested. From the percentage of surface spins (23\% for C/V/S and $26 \%$ for hollow MNPs), a similar distribution and effect on EB generation in these spins in both MNPs can be inferred. The surface spin contribution in EB generation, when entering a spin-glass-like state, should not be ignored, due to the high values obtained. Compared to the work reported by Ong et al. [23], a key role of surface spins to inducing an improvement in $\mathrm{H}_{\mathrm{EB}}$ was observed. Furthermore, the results obtained from the frozen spins show a nanograin structure in the shell of the MNPs whose spins were coupled to each other. Due to the presence of the Fe core reversible spins, a lower percentage of frozen spins in $\mathrm{C} / \mathrm{V} / \mathrm{S}$ 
MNPs was obtained. However, the EB generation process due to the frozen spins of the nanograins must be similar in both MNPs. The significant difference resides in the presence of the Fe core. In the C/V/S MNPs, there was a discontinuous coupling between the Fe (FM) core and the iron oxide (FI) shell, which was responsible for the higher $\mathrm{H}_{\mathrm{EB}}$ values obtained in the C/V/S MNPs. However, this coupling did not dominate in the generation of $\mathrm{EB}$, since the $\mathrm{H}_{\mathrm{EB}}$ values obtained were not significantly higher.
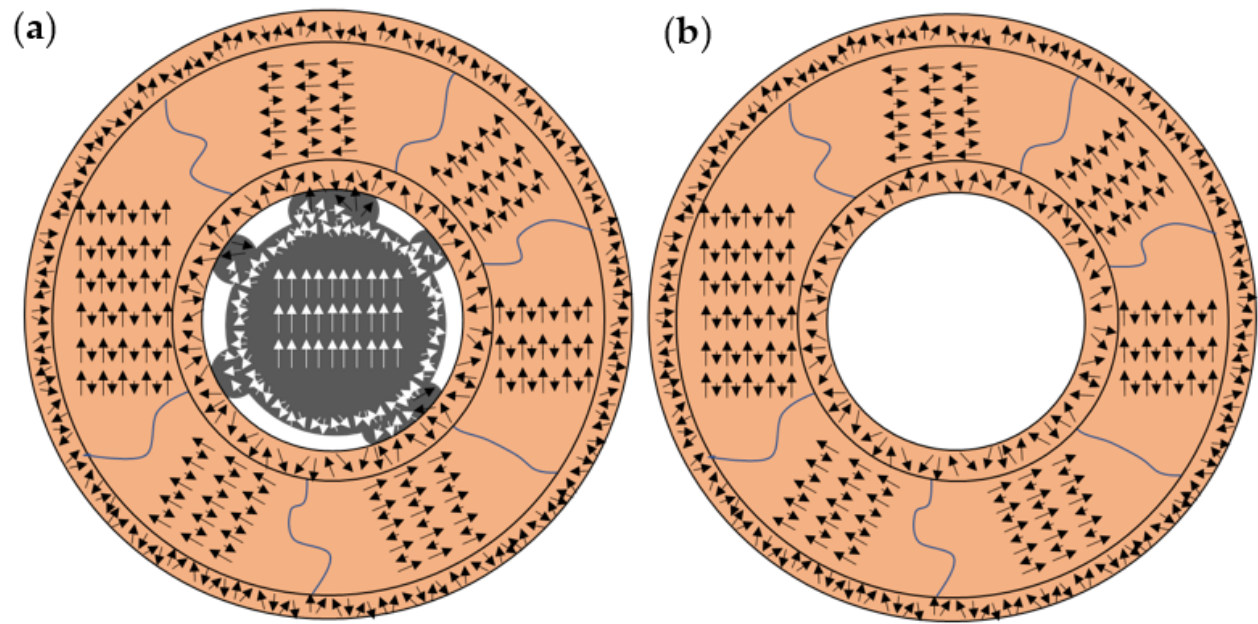

Figure 10. Schematic illustration of the different spin arrangements in (a) core/void/shell and in (b) hollow MNPs, with inner magnetic domains, external surfaces (inner and outer), and core magnetic domain.

\section{Conclusions}

In summary, we presented the study of the intrinsic EB effect on iron oxide (with $\mathrm{Fe}_{3} \mathrm{O}_{4}$ or $\gamma-\mathrm{Fe}_{2} \mathrm{O}_{3}$ as the main magnetic phase) hollow MNPs $\left(\mathrm{H}_{\mathrm{EB}}=444 \mathrm{Oe}\right)$ with improved magnetization $\left(50 \mathrm{emu} / \mathrm{g}\right.$ ) within an extended range of $\mathrm{H}_{\mathrm{FC}}$ (from 0.1 to $50 \mathrm{kOe}$ ). The number of surface spins present in the hollow MNPs and in the precursors with core/void/shell structure were studied. The important role of the surface spins in the magnetic properties of MNPs and, in turn, in the enhancement of $\mathrm{H}_{\mathrm{EB}}$ in hollow MNPs, was inferred. On the other hand, the dependence of frozen spins on the cooling field and temperature was measured and found to be similar to the relationship between $\mathrm{H}_{\mathrm{EB}}$ with $\mathrm{H}_{\mathrm{FC}}$. This highlighted the notable influence of frozen spins on EB generation. Moreover, the relationship between $\mathrm{H}_{\mathrm{EB}}$ and a large interval of cooling fields revealed the maximum $\mathrm{H}_{\mathrm{EB}}$ values at particular $\mathrm{H}_{\mathrm{FC}}$ and showed new trends, not reported so far, in iron-oxide-based hollow MNPs. Therefore, this finding can be useful in the design of hollow iron oxide MNPs with $\mathrm{H}_{\mathrm{EB}-\max }$ and $\mathrm{H}_{\mathrm{FC} \text {-max }}$ for in-demand applications.

Supplementary Materials: The following are available online at https:/ / www.mdpi.com/article / 10.3390/nano12030456/s1. Figure S1: Temperature dependence of the real component $\chi^{\prime}(\mathrm{T})$ of (a) $\mathrm{C} / \mathrm{V} / \mathrm{S}$ MNPs and (b) hollow MNPs at 1 Oe. Insets show the imaginary component $\chi^{\prime \prime}(\mathrm{T})$ of the magnetic susceptibility of C/V/S MNPs and hollow MNPs; Figure S2: Hysteresis loops of solid iron oxide based MNPs (black points) and hollow iron oxide based MNPs (red points) at $5 \mathrm{~K}$ and with $\mathrm{H}_{\mathrm{FC}}=10 \mathrm{kOe}$ in the range of (a) -50 and $50 \mathrm{kOe}$. For clarity the range between -5 and $5 \mathrm{kOe}$ is shown in (b).

Author Contributions: Conceptualization-P.G.A. and Y.P.; supervision and formal analysis-Y.P.; writing-P.G.A., M.A.G.G., Á.A.P., J.S.G., Y.P. and J.R.; investigation and development-P.G.A., M.A.G.G., Á.A.P. and J.S.G.; supervision and group direction: J.R. All authors have read and agreed to the published version of the manuscript.

Funding: This work was supported by the European Commission under the BOW project, (FETPROACTEIC-05-2019, Grant 952183), and partially supported by the Spanish Ministry of Science and Innovation (PID2020-112626RB-C21), Modalities «Research Challenges» and «Knowledge Generation», 
and the Regional Consellería de Innovacion Program for the Grupos de Referencia Competitiva 2021-GRC2021 project of Xunta de Galicia.

Institutional Review Board Statement: Not applicable.

Informed Consent Statement: Not applicable.

Data Availability Statement: Not applicable.

Acknowledgments: The authors would like to thank Susana Yañez Vilar for her help with the magnetic characterizations.

Conflicts of Interest: The authors declare no conflict of interest.

\section{References}

1. Binek, C.; Hochstrat, A.; Chen, X.; Borisov, P.; Kleemann, W.; Doudin, B. Electrically controlled exchange bias for spintronic applications. J. Appl. Phys. 2005, 97, 10. [CrossRef]

2. Wei, Z.; Sharma, A.; Nunez, A.S.; Haney, P.M.; Duine, R.A.; Bass, J.; MacDonald, A.H.; Tsoi, M. Changing Exchange Bias in Spin Valves with an Electric Current. Phys. Rev. Lett. 2007, 98, 116603. [CrossRef] [PubMed]

3. De Araujo, C.I.L.; Alves, S.G.; Buda-Prejbeanu, L.D.; Dieny, B. Multilevel Thermally Assisted Magnetoresistive Random-Access Memory Based on Exchange-Biased Vortex Configurations. Phys. Rev. Appl. 2016, 6, 024015. [CrossRef]

4. Skumryev, V.; Stoyanov, S.; Zhang, Y.; Hadjipanayis, G.; Givord, D.; Nogues, J. Beating the superparamagnetic limit with exchange bias. Nature 2003, 423, 850-853. [CrossRef] [PubMed]

5. Phan, M.H.; Alonso, J.; Khurshid, H.; Lampen-Kelley, P.; Chandra, S.; Stojak Repa, K.; Nemati, Z.; Das, R.; Iglesias, Ó.; Srikanth, H. Exchange Bias Effects in Iron Oxide-Based Nanoparticle Systems. Nanomaterials 2016, 6, 221. [CrossRef]

6. Nogues, J.; Lederman, D.; Moran, T.J.; Schuller, I.K. Positive Exchange Bias in FeF2-Fe Bilayers. Phys. Rev. Lett. 1996, 76, 4624-4627. [CrossRef]

7. Baltz, V.; Sort, J.; Landis, S.; Rodmacq, B.; Dieny, B. Tailoring Size Effects on the Exchange Bias in Ferromagnetic-Antiferromagnetic $<100$ nmNanostructures. Phys. Rev. Lett. 2005, 94, 117201. [CrossRef]

8. Vasilakaki, M.; Trohidou, K.N. Numerical study of the exchange-bias effect in nanoparticles with ferromagnetic core/ferrimagnetic disordered shell morphology. Phys. Rev. B 2009, 79, 144402. [CrossRef]

9. Troitiño, N.F.; Rivas-Murias, B.; Rodríguez-González, B.; Salgueiriño, V. Exchange Bias Effect in CoO@ $\mathrm{Fe}_{3} \mathrm{O} 4 \mathrm{Core-Shell}$ Octahedron-Shaped Nanoparticles. Chem. Mater. 2014, 26, 5566-5575. [CrossRef]

10. Meiklejohn, W.H.; Bean, C.P. New Magnetic Anisotropy. Phys. Rev. 1957, 105, 904-913. [CrossRef]

11. Vázquez-Vázquez, C.; López-Quintela, M.A.; Buján-Núñez, M.D.C.; Rivas, J. Finite size and surface effects on the magnetic properties of cobalt ferrite nanoparticles. J. Nanopart. Res. 2011, 13, 1663-1676. [CrossRef]

12. Rinaldi-Montes, N.; Gorria, P.; Martínez-Blanco, D.; Fuertes, A.B.; Barquín, L.F.; Puente-Orench, I.; Blanco, J.A. Bridging exchange bias effect in $\mathrm{NiO}$ and $\mathrm{Ni}($ core)@NiO(shell) nanoparticles. J. Magn. Magn. Mater. 2016, 400, 236-241. [CrossRef]

13. Kachkachi, H.; Ezzir, A.; Noguès, M.; Tronc, E. Surface effects in nanoparticles: Application to maghemite -Fe O. Eur. Phys. J. B 2000, 14, 681-689. [CrossRef]

14. Fiorani, D.; Testa, A.M.; Tronc, E.; Lucari, F.; D'Orazio, F.; Nogués, M. Spin freezing in maghemite nanoparticle systems. J. Magn. Magn. Mater. 2001, 226-230, 1942-1944. [CrossRef]

15. Brice-Profeta, S.; Arrio, M.-A.; Tronc, E.; Menguy, N.; Letard, I.; Moulin, C.C.D.; Noguès, M.; Chanéac, C.; Jolivet, J.-P.; Sainctavit, P. Magnetic order in nanoparticles: A XMCD study. J. Magn. Magn. Mater. 2005, 288, 354-365. [CrossRef]

16. Dormann, J.; Cherkaoui, R.; Spinu, L.; Noguès, M.; Lucari, F.; D'Orazio, F.; Fiorani, D.; García-Santiago, A.; Tronc, E.; Jolivet, J. From pure superparamagnetic regime to glass collective state of magnetic moments in $\gamma-\mathrm{Fe}_{2} \mathrm{O}_{3}$ nanoparticle assemblies. J. Magn. Magn. Mater. 1998, 187, L139-L144. [CrossRef]

17. Goya, G.; Berquo, T.S.; Fonseca, F.C.; Morales, M.D.P. Static and dynamic magnetic properties of spherical magnetite nanoparticles. J. Appl. Phys. 2003, 94, 3520-3528. [CrossRef]

18. Dutta, P.K.; Pal, S.C.; Seehra, M.S.; Shah, N.; Huffman, G.P. Size dependence of magnetic parameters and surface disorder in magnetite nanoparticles. J. Appl. Phys. 2009, 105, 07B501. [CrossRef]

19. Zysler, R.; Winkler, E.; Mansilla, M.V.; Fiorani, D. Surface effect in the magnetic order of antiferromagnetic nanoparticles. Phys. B Condens. Matter 2006, 384, 277-281. [CrossRef]

20. Ghoshani, M.; Sánchez, E.H.; Lee, S.S.; Singh, G.; Yaacoub, N.; Peddis, D.; Mozaffari, M.; Binns, C.; De Toro, J.A.; Normile, P.S. On the detection of surface spin freezing in iron oxide nanoparticles and its long-term evolution under ambient oxidation. Nanotechnology 2021, 32, 065704. [CrossRef]

21. Shendruk, T.; Desautels, R.; Southern, B.W.; van Lierop, J. The effect of surface spin disorder on the magnetism of $\gamma-\mathrm{Fe}_{2} \mathrm{O}_{3}$ nanoparticle dispersions. Nanotechnology 2007, 18, 455704. [CrossRef]

22. Martínez, B.; Obradors, X.; Balcells, L.; Rouanet, A.; Monty, C. Low Temperature Surface Spin-Glass Transition in $\gamma-\mathrm{Fe}_{2} \mathrm{O}_{3}$ Nanoparticles. Phys. Rev. Lett. 1998, 80, 181-184. [CrossRef] 
23. Ong, Q.K.; Wei, A.; Lin, X.-M. Exchange bias inFe $/ \mathrm{Fe}_{3} \mathrm{O} 4$ core-shell magnetic nanoparticles mediated by frozen interfacial spins. Phys. Rev. B 2009, 80, 134418. [CrossRef]

24. Sayed, F.; Labaye, Y.; Hassan, R.S.; Hassan, F.E.H.; Yaacoub, N.; Greneche, J.-M. Size and thickness effect on magnetic structures of maghemite hollow magnetic nanoparticles. J. Nanopart. Res. 2016, 18, 279. [CrossRef]

25. Khurshid, H.; Phan, M.-H.; Mukherjee, P.; Srikanth, H. Tuning exchange bias in $\mathrm{Fe} / \gamma-\mathrm{Fe}_{2} \mathrm{O}_{3}$ core-shell nanoparticles: Impacts of interface and surface spins. Appl. Phys. Lett. 2014, 104, 072407. [CrossRef]

26. Khurshid, H.; Li, W.; Chandra, S.; Phan, M.-H.; Hadjipanayis, G.C.; Mukherjee, P.; Srikanth, H. Mechanism and controlled growth of shape and size variant core/shell $\mathrm{FeO} / \mathrm{Fe}_{3} \mathrm{O} 4$ nanoparticles. Nanoscale 2013, 5, 7942-7952. [CrossRef]

27. Hwang, Y.; Angappane, S.; Park, J.; An, K.; Hyeon, T.; Park, J.-G. Exchange bias behavior of monodisperse $\mathrm{Fe}_{3} \mathrm{O}_{4} / \gamma-\mathrm{Fe}_{2} \mathrm{O}_{3}$ core/shell nanoparticles. Curr. Appl. Phys. 2012, 12, 808-811. [CrossRef]

28. Panagiotopoulos, I.; Basina, G.; Alexandrakis, V.; Devlin, E.; Hadjipanayis, G.; Colak, L.; Niarchos, D.; Tzitzios, V. Synthesis and Exchange Bias in $\gamma-\mathrm{Fe}_{2} \mathrm{O}_{3} / \mathrm{CoO}$ and Reverse $\mathrm{CoO} / \gamma-\mathrm{Fe}_{2} \mathrm{O}_{3}$ Binary Nanoparticles. J. Phys. Chem. C 2009, 113, 14609-14614. [CrossRef]

29. Lak, A.; Kraken, M.; Ludwig, F.; Kornowski, A.; Eberbeck, D.; Sievers, S.; Litterst, F..; Weller, H.; Schilling, M. Size dependent structural and magnetic properties of $\mathrm{FeO}-\mathrm{Fe}_{3} \mathrm{O} 4$ nanoparticles. Nanoscale 2013, 5, 12286-12295. [CrossRef]

30. Sun, X.; Huls, N.F.; Sigdel, A.; Sun, S. Tuning Exchange Bias in Core/Shell FeO/Fe ${ }_{3} \mathrm{O} 4$ Nanoparticles. Nano Lett. 2012, 12, 246-251. [CrossRef]

31. Kavich, D.W.; Dickerson, J.H.; Mahajan, S.V.; Hasan, S.A.; Park, J.-H. Exchange bias of singly inverted FeO/Fe 304 core-shell nanocrystals. Phys. Rev. B 2008, 78, 174414. [CrossRef]

32. Nemati, Z.; Khurshid, H.; Alonso, J.; Phan, M.H.; Mukherjee, P.; Srikanth, H. From core/shell to hollow Fe $/ \gamma-\mathrm{Fe}_{2} \mathrm{O}_{3}$ nanoparticles: Evolution of the magnetic behavior. Nanotechnology 2015, 26, 405705. [CrossRef] [PubMed]

33. Ong, Q.K.; Lin, X.-M.; Wei, A. Role of Frozen Spins in the Exchange Anisotropy of Core-Shell Fe@Fe ${ }_{3} \mathrm{O} 4$ Nanoparticles. J. Phys. Chem. C 2011, 115, 2665-2672. [CrossRef] [PubMed]

34. Khurshid, H.; Li, W.; Phan, M.H.; Mukherjee, P.; Hadjipanayis, G.C.; Srikanth, H. Surface spin disorder and exchange-bias in hollow maghemite nanoparticles. Appl. Phys. Lett. 2012, 101, 022403. [CrossRef]

35. Jaffari, G.H.; Ceylan, A.; Bui, H.P.; Beebe, T.P., Jr.; Ozcan, S.; Shah, S.I. Non-equilibrium cation distribution and enhanced spin disorder in hollow CoFe2O4nanoparticles. J. Phys. Condens. Matter 2012, 24, 336004. [CrossRef]

36. Jaffari, G.H.; Ceylan, A.; Ni, C.; Shah, S.I. Enhancement of surface spin disorder in hollow $\mathrm{NiFe}_{2} \mathrm{O}_{4}$ nanoparticles. J. Appl. Phys. 2010, 107, 13910. [CrossRef]

37. Cabot, A.; Alivisatos, A.P.; Puntes, V.F.; Balcells, L.; Iglesias, Ò.; Labarta, A. Magnetic domains and surface effects in hollow maghemite nanoparticles. Phys. Rev. B 2009, 79, 094419. [CrossRef]

38. Sayed, F.; Yaacoub, N.; Labaye, Y.; Hassan, R.S.; Singh, G.; Kumar, P.A.; Greneche, J.M.; Mathieu, R.; Hadjipanayis, G.C.; Agostinelli, E.; et al. Surface Effects in Ultrathin Iron Oxide Hollow Nanoparticles: Exploring Magnetic Disorder at the Nanoscale. J. Phys. Chem. C 2018, 122, 7516-7524. [CrossRef]

39. Iglesias, O.; Labarta, A.; Batlle, X. Exchange Bias Phenomenology and Models of Core/Shell Nanoparticles. J. Nanosci. Nanotechnol. 2008, 8, 2761-2780. [CrossRef]

40. Mumtaz, A.; Maaz, K.; Janjua, B.; Hasanain, S.; Bertino, M. Exchange bias and vertical shift in CoFe2O4 nanoparticles. J. Magn. Magn. Mater. 2007, 313, 266-272. [CrossRef]

41. Wang, H.; Zhu, T.; Zhao, K.; Wang, W.N.; Wang, C.S.; Wang, Y.J.; Zhan, W.S. Surface spin glass and exchange bias in Fe ${ }_{3} \mathrm{O} 4$ nanoparticles compacted under high pressure. Phys. Rev. B 2004, 70, 092409. [CrossRef]

42. Del Bianco, L.; Fiorani, D.; Testa, A.M.; Bonetti, E.; Signorini, L. Field-cooling dependence of exchange bias in a granular system of Fe nanoparticles embedded in an Fe oxide matrix. Phys. Rev. B 2004, 70, 052401. [CrossRef]

43. Peng, S.; Sun, S. Synthesis and Characterization of Monodisperse Hollow $\mathrm{Fe}_{3} \mathrm{O}_{4}$ Nanoparticles. Angew. Chem. Int. Ed. 2007, 46, 4155-4158. [CrossRef] [PubMed]

44. Brand, R.A. Normos Mössbauer Fitting Program. Univ.Duisburg. 2002. Available online: https://www.uni-due.de/ \{\{hm236ap/ keune/deutsch/Bran/r.a.brand.homepage.htm\#Normos (accessed on 21 January 2022).

45. Coker, V.S.; Bell, A.M.T.; Pearce, C.I.; Pattrick, R.A.; van der Laan, G.; Lloyd, J. Time-resolved synchrotron powder X-ray diffraction study of magnetite formation by the Fe(III)-reducing bacterium Geobacter sulfurreducens. Am. Mineral. 2008, 93, 540-547. [CrossRef]

46. Swanson, H.E.; McMurdie, H.F.; Morris, M.C.; Evans, E.H. Standard X-ray Diffraction Powder Patterns; U.S. Department of Commerce, National Bureau of Standards: Gaithersburg, MD, USA, 1967. [CrossRef]

47. Maity, D.; Choo, S.G.; Yi, J.; Ding, J.; Xue, J.M. Synthesis of magnetite nanoparticles via a solvent-free thermal decomposition route. J. Magn. Magn. Mater. 2009, 321, 1256-1259. [CrossRef]

48. Berti, I.O.P.D.; Cagnoli, M.V.; Pecchi, G.; Alessandrini, J.L.; Stewart, S.J.; Bengoa, J.F.; Marchetti, S.G. Alternative low-cost approach to the synthesis of magnetic iron oxide nanoparticles by thermal decomposition of organic precursors. Nanotechnology 2013, 24, 175601. [CrossRef]

49. Wang, L.; Bao, J.; Wang, L.; Zhang, F.; Li, Y. One-Pot Synthesis and Bioapplication of Amine-Functionalized Magnetite Nanoparticles and Hollow Nanospheres. Chem. Eur. J. 2006, 12, 6341-6347. [CrossRef] 
50. Singh, L.H.; Govindaraj, R.; Amarendra, G.; Sundar, C.S. Local structure and magnetic properties of cubic iron oxide nanoparticles formed in zeolite as deduced using Mössbauer spectroscopy. Appl. Phys. Lett. 2013, 103, 193104. [CrossRef]

51. Mikhaylova, M.; Kim, D.K.; Bobrysheva, N.; Osmolowsky, M.; Semenov, V.; Tsakalakos, T.; Muhammed, M. Superparamagnetism of Magnetite Nanoparticles: Dependence on Surface Modification. Langmuir 2004, 20, 2472-2477. [CrossRef]

52. Joos, A.; Rümenapp, C.; Wagner, F.E.; Gleich, B. Characterisation of iron oxide nanoparticles by Mössbauer spectroscopy at ambient temperature. J. Magn. Magn. Mater. 2016, 399, 123-129. [CrossRef]

53. Khurshid, H.; Lampen-Kelley, P.; Iglesias, O.; Alonso, J.; Phan, M.-H.; Sun, C.-J.; Saboungi, M.-L.; Srikanth, H. Spin-glass-like freezing of inner and outer surface layers in hollow $\gamma-\mathrm{Fe}_{2} \mathrm{O}_{3}$ nanoparticles. Sci. Rep. 2015, 5, 15054. [CrossRef] [PubMed] 